\title{
Overview of the Icing and Flow Quality Improvements Program for the NASA Glenn Icing Research Tunnel
}

Thomas B. Irvine, Susan L. Kevdzija, and David W. Sheldon Glenn Research Center, Cleveland, Ohio

David A. Spera

Dynacs Engineering Company, Inc., Brook Park, Ohio 
Since its founding, NASA has been dedicated to the advancement of aeronautics and space science. The NASA Scientific and Technical Information (STI) Program Office plays a key part in helping NASA maintain this important role.

The NASA STI Program Office is operated by Langley Research Center, the Lead Center for NASA's scientific and technical information. The NASA STI Program Office provides access to the NASA STI Database, the largest collection of aeronautical and space science STI in the world. The Program Office is also NASA's institutional mechanism for disseminating the results of its research and development activities. These results are published by NASA in the NASA STI Report Series, which includes the following report types:

- TECHNICAL PUBLICATION. Reports of completed research or a major significant phase of research that present the results of NASA programs and include extensive data or theoretical analysis. Includes compilations of significant scientific and technical data and information deemed to be of continuing reference value. NASA's counterpart of peerreviewed formal professional papers but has less stringent limitations on manuscript length and extent of graphic presentations.

- TECHNICAL MEMORANDUM. Scientific and technical findings that are preliminary or of specialized interest, e.g., quick release reports, working papers, and bibliographies that contain minimal annotation. Does not contain extensive analysis.

- CONTRACTOR REPORT. Scientific and technical findings by NASA-sponsored contractors and grantees.
- CONFERENCE PUBLICATION. Collected papers from scientific and technical conferences, symposia, seminars, or other meetings sponsored or cosponsored by NASA.

- SPECIAL PUBLICATION. Scientific, technical, or historical information from NASA programs, projects, and missions, often concerned with subjects having substantial public interest.

- TECHNICAL TRANSLATION. Englishlanguage translations of foreign scientific and technical material pertinent to NASA's mission.

Specialized services that complement the STI Program Office's diverse offerings include creating custom thesauri, building customized data bases, organizing and publishing research results ... even providing videos.

For more information about the NASA STI Program Office, see the following:

- Access the NASA STI Program Home Page at http://www.sti.nasa.gov

- E-mail your question via the Internet to help@sti.nasa.gov

- Fax your question to the NASA Access Help Desk at 301-621-0134

- Telephone the NASA Access Help Desk at 301-621-0390

- Write to:

NASA Access Help Desk

NASA Center for AeroSpace Information 7121 Standard Drive

Hanover, MD 21076 
NASA/TM-2001-210686

\section{Overview of the Icing and Flow Quality Improvements Program for the NASA Glenn Icing Research Tunnel}

Thomas B. Irvine, Susan L. Kevdzija, and David W. Sheldon

Glenn Research Center, Cleveland, Ohio

David A. Spera

Dynacs Engineering Company, Inc., Brook Park, Ohio

Prepared for the

39th Aerospace Sciences Meeting and Exhibit

sponsored by the American Institute of Aeronautics and Astronautics

Reno, Nevada, January 8-11, 2001

National Aeronautics and

Space Administration

Glenn Research Center 
Available from

NASA Center for Aerospace Information

National Technical Information Service 5285 Port Royal Road Springfield, VA 22100

Hanover, MD 21076 Price Code: A03

Price Code: A03 


\title{
OVERVIEW OF THE ICING AND FLOW QUALITY IMPROVEMENTS PROGRAM FOR THE NASA-GLENN ICING RESEARCH TUNNEL
}

\author{
Thomas B. Irvine, Susan L. Kevdzija, and David W. Sheldon \\ National Aeronautics and Space Administration \\ Glenn Research Center \\ Cleveland, Ohio 44135 \\ David A. Spera \\ Dynacs Engineering Company, Inc. \\ Brook Park, Ohio 44142
}

\begin{abstract}
Major upgrades were made in 1999 to the 6 - $\mathrm{ft}$ by $9-\mathrm{ft}$ $(1.8 \mathrm{~m}$ by $2.7 \mathrm{~m}$ ) Icing Research Tunnel (IRT) at the NASA Glenn Research Center. These included replacement of the electronic controls for the variablespeed drive motor, replacement of the heat exchanger, complete replacement and enlargement of the leg of the tunnel containing the new heat-exchanger, the addition of flow-expanding and flow-contracting turning vanes upstream and downstream of the heat exchanger, respectively, and the addition of fan outlet guide vanes (OGV's).

This paper describes the rationale behind this latest program of IRT upgrades and the program's requirements and goals. An overview is given of the scope of work undertaken by the design and construction contractors, the scale-model IRT (SMIRT) design verification program, the comprehensive reactivation test program initiated upon completion of construction, and the overall management approach followed.
\end{abstract}

\section{Nomenclature}

A to $D$ 1st to 4 th tunnel comers

HX heat exchanger

IRT Icing Research Tunnel (6' x 9')

OGV fan outlet guide vane

SMIRT Scale Model Icing Research Tunnel (1/10 th scale)

\section{Introduction}

Research in aircraft icing and component icing qualification tests have been conducted in the Icing Research Tunnel (IRT) at the NASA Glenn Research Center (GRC; previously the Lewis Research Center) for over fifty-five years. ${ }^{1}$ A wide variety of civilian and military aircraft components and ice-protection systems have been tested in the IRT under icing conditions. Test articles are usually full-scale or nearly full-scale in size, because scaling laws for icing are subjects of current research.

In addition to NASA, organizations sponsoring tests in the IRT include the FAA, the Department of Defense, and both large and small manufacturers of airframes and aircraft engines. Private organizations compensate NASA for the use of the IRT in accordance with formal agreements authorized by the Space Act of 1958. In recent years the IRT has been one of NASA's busiest wind tunnels. The bar chart in Figure 1 shows the number of hours of running time in the IRT in each year since 1990.

\section{Previous Upgrades and Long-Range Plans}

Although the basic structure of the IRT dates back to 1944, many components of the facility have been upgraded since that time. In addition, instrumentation, controls, and data acquisition systems have been regularly upgraded to include current technology. Major upgrades to the IRT are listed in Table 1. The fan drive motor was replaced in 1986, doubling the available power to 5,000 horsepower. In 1992 and 1993 the insulation on a large portion of the tunnel was upgraded and an external force balance was installed. In 1993 new fan blades were installed with pitch angles modified to use all the available power in the drive motor. This resulted in an increase in maximum tunnel airspeed from 305 to 420 miles per hour.

In 1994 an IRT Long-Range Improvement Plan was developed, in which the following four goals were established: (1) Increasing the size of the uniform icing cloud in the test section, (2) improving and increasing the capability of the spray system, (3) improving the 
tunnel's aerodynamic flow quality under dry operating conditions, and (4) increasing the maximum airspeed in the tunnel. This long-range planning resulted in the successful advocacy for a new spraybar system $(1996 / 97)^{2}$ and a replacement heat exchanger (1999), as noted in Table 1. The first three of the goals of the long-range plan have now been met through the successful completion of these latest two upgrade programs. It is now clear that the fourth goal, that of increasing the tunnel's maximum airspeed above the $430 \mathrm{mph}$ achieved in 1994, is not achievable with the current drive motor. Also, the noise levels in the control room during operations at airspeeds above $400 \mathrm{mph}$ were found to be too high for sustained testing. After the new heat exchanger was installed in 1999 there was a further reduction in maximum airspeed to about $390 \mathrm{mph}$ under dry operating conditions. However, during icing sprays the tunnel airspeed does not decrease significantly with the buildup of frost on the new heat exchanger. Therefore, tunnel operations during icing tests continue to meet most customer test matrix requirements.

\section{$\underline{\text { Scope }}$}

This paper describes the rationale behind the 1999 program of IRT upgrades and the program's requirements and goals. An overview is given of the scope of work undertaken by the design and construction contractors, the scale-model IRT (SMIRT) design verification program, the comprehensive reactivation test program initiated upon completion of construction, and the overall management approach followed.

\section{Airflow around the IRT Loop}

One of the major objectives of the 1999 program of IRT upgrades is to improve flow quality within the Test Section by reducing upstream distortions in the air flow, including variations in airspeed, variations in air temperature, flow angularity, and turbulence. For this reason, a brief description is in order of the flow around the IRT loop, entering and leaving the Test Section.

A plan view of the original configuration of the IRT is shown schematically in Figure 2(a). In this plan view, air circulates in a counter-clockwise direction around the tunnel loop, which is rectangular in cross-section except at the drive fan where it is circular. Starting at the Stilling Chamber in the lower left comer, lowvelocity chilled air passes through the spray bar section where heated air and water droplets are sprayed into the stream from an array of nozzles.

The airflow carrying a cloud of super-cooled water droplets is then accelerated in the Convergence Section and enters the Test Section, at airspeeds up to approximately $400 \mathrm{mph}$. In the Test Section, water droplets freeze on contact with a test article that is usually mounted on the turntable in the tunnel floor and rotated to the desired angle of attack. The airflow then exits the Test Section and begins its deceleration in the Diffuser, which extends through Corners A and B. Each of these corners contains a cascade of vanes that turn the flow 90 degrees with minimal losses and turbulence.

Downstream of Corner B the duct shape transitions from rectangular to circular, and the flow enters the Fan Section through a radial array of fan inlet guide vanes (IGVs). Here the airflow is swirled clockwise (looking downstream), which partially counters the swirl imparted later by the counter-clockwise rotation of the fan blades and reduces flow angularity downstream. The total pressure in the air stream is raised by the fan, in the amount required to offset pressure losses that occur throughout the rest of the tunnel loop. Air temperature is also increased as a result of the heat of compression. This is the main source of heat that must be removed from the tunnel by the heat exchanger further downstream.

The outflow of the fan passes through a transition duct, which changes in cross-sectional shape from circular to rectangular, and then through the Vent Tower Section. The movable sidewalls of the vent tower are normally closed, but after icing tests they can be moved inward to allow outside air to mix with the flow and help dry out the tunnel.

From the Vent Tower the flow passes through the turning vanes in Corner $\mathrm{C}$ and then through the heat exchanger, where its temperature is lowered. As illustrated in Figures 2(b) and (c), the fin-tube panels of the original heat exchanger are arranged in the shape of a "W" laid on its side. This increases the flow areas of the individual panels and thereby decreases airspeeds over the coolant tubes to an acceptable level. The flow then passes through the turning vanes in Corner $\mathrm{D}$ and back to the Stilling Chamber.

\section{Deficiencies to be Corrected by Upgrades}

In recent years, deficiencies in the operation and maintenance of the IRT clearly indicated that certain components in the supply legs of the tunnel - from the fan to the Stilling Chamber - needed to be replaced and improved. The current upgrade program was designed to correct the following deficiencies:

\section{Obsolete Electronic Controls for the Fan Motor}

The 5,000-hp synchronous motor driving the IRT fan was installed in 1986 with a "Varichron" AC-DC-AC electrical system for variable-speed operation. The microcomputer controlling all electrical system operations, which was designed according to the state 
of the technology in the early 1980s, had become obsolete. The company that owned the Varichron design was phasing out technical support for this control system. Because of their age, the electronic components in the microcomputer were failing in increasing numbers with each passing year. Troubleshooting and diagnostics were becoming more and more difficult. Spare and replacement parts were very hard to locate and, when found, were extremely expensive.

\section{Deterioration of the Heat Exchanger}

The Carrier Corporation installed the large copper tubecopper fin heat exchanger, with a nominal refrigeration capability of 2100 tons, in the IRT in 1943. After more than 50 years of service, the network of copper tubes was deteriorating to the point where the repair or closing-off of leaking tubes was responsible for about 100 hours of tunnel downtime each year. Leaks were occurring at silver-soldered joints at the end turns of the tubes, which were caused by the incompatibility of the R-134a coolant and silver solder.

\section{Corrosion of the C-D Leg Floor and Ceiling}

Over the years, residual water from icing tests had badly corroded the steel floor plates in the C-D leg. Rainwater had also seeped under the roofing material, saturating of the roof insulation and corroding the ceiling plates. Condensation on the outer sides of the steel plates also added to the corrosion. Local repairs were made, but it was clear that the steel structure in the C-D leg could not be easily modified to support a new heat exchanger. In addition, the existing heat exchanger and the surrounding steel structure were so closely connected that it was impractical to replace the heat exchanger without replacing a large portion of the structure as well.

\section{Flow Distortions from the W-Shaped Heat Exchanger and Motor Stand Leg Fairings}

The airflow in the supply legs, from the vent tower section downstream of the fan through the refrigeration heat exchanger and into the stilling chamber has been shown to be unevenly distributed across duct flow areas. ${ }^{3,4}$ The two main causes of these flow distortions were the "W" shape of the heat exchanger and the presence of two large fairings around the legs of the fan motor support stand below the fan motor nacelle. These leg fairings are shown in Figure 3. The nonuniform distribution of airspeed across the heat exchanger produced non-uniform cooling rates, and this required a complicated balancing of the coolant flow through the various HX panels in order to achieve a uniform air temperature in the Test Section.

\section{IRT Upgrade Program}

\section{Objectives}

The objectives of the 1999 IRT upgrade program, in priority order, are as follows:

1. Modernize the electronic controls of the fan motor and eliminate the excessive maintenance time and costs required now to keep the existing, obsolete Varichron microprocessor operational.

2. Replace the aging heat exchanger and eliminate the excessive downtime required now for repairing leaks.

3. Replace the corroded and leaking steel tunnel structure in the C-D leg, particularly in the floor and ceiling plates.

4. Improve the quality of the airflow into the spraybars, removing distortions and turbulence caused by the " $W$ " shape of the original heat exchanger.

5. Improve the uniformity of temperature in the airflow into the spraybars and the Test Section.

6. Improve the insulation on the walls and roof of the C-D leg and add insulation to the floor, reducing the thermal load on the heat exchanger.

The goal of the program is to obtain these objectives without reducing the overall performance of the IRT in its icing environment. The various phases of the current upgrade program are listed in Table 2, together with the performing organizations, dates, and (where applicable) costs for each. A brief description of each phase follows.

\section{Conceptual Design Phase}

Feasibility and conceptual design studies for a replacement heat exchanger were conducted in-house as early as $1994 .^{5}$ These studies helped define the overall scope, geometric configuration, and objectives of the tunnel upgrade program. The selected configuration for the IRT upgrades is shown schematically in Figure 4. The original W-shaped heat exchanger was replaced with a flat-faced heat exchanger in order to eliminate the large flow distortions caused by the comer structures joining the original $\mathrm{HX}$ panels. The new heat exchanger was configured as two side-by-side units, each with its own coolant supply and return pipes. Coolant flows from a supply header at an outside wall through parallel horizontal tubes extending to the middle of the tunnel and then back to a return header, in a single pass.

The two HX units were offset from one another in order to provide access for maintenance that might be required on the end turns of the coolant tubes. By 
offsetting the units in the streamwise direction there is almost no loss of active flow area, as would be the case for a maintenance corridor between units that are not offset.

The major disadvantage of changing to a flat heat exchanger is that the width of the C-D leg had to be increased. The " $W$ " shape of the original heat exchanger (Fig. 2(c)) was selected because it provided almost three times the flow area of a flat heat exchanger of the same height, for each foot of tunnel width. In the original $\mathrm{HX}$, the fins at the entrance face of each slanted panel turned the flow normal to the panel, and another set of curved fins on the exit face returned the flow to a horizontal direction. To obtain the required flow area with a flat $\mathrm{HX}$, the width of the tunnel duct between Corners $C$ and D was increased from 29.2 to 49.2 feet $(8.9$ to $15.0 \mathrm{~m})$, the maximum width possible because of an adjoining building. Even with this added width, airspeeds over the coolant tubes in the replacement $\mathrm{HX}$ are about 35 percent higher than in the original $\mathrm{HX}$ for the same tunnel airspeed, making drag losses (proportional to the square of the local airspeed) a significant design consideration.

The added width in the C-D leg necessitated two new cascades of turning vanes in Corners C and D. Each cascade of vanes is $57.2 \mathrm{ft}(17.4 \mathrm{~m})$ in length. The selected aerodynamic design consists of 16 large vanes in each comer, with the cross-sections illustrated in Figures 5(a) and (b). These vanes were specifically designed to slow down the flow entering the $\mathrm{HX}$ and then speed up the flow entering the Stilling Chamber. ${ }^{6}$ As shown in Figure 5(a), the flow expands through Corner $\mathrm{C}$, producing an average outflow-to-inflow airspeed ratio of 0.59 . Figure 5(b) shows that at Corner $\mathrm{D}$ the flow contracts, and the average outflowto-inflow airspeed ratio is 1.69 .

The leading edge shapes of the new vanes in Corners $C$ and $D$ are designed to be relatively insensitive to the angle of the incoming flow, and the advanced converging-diverging shape of the flow path between adjacent vanes changes the flow direction and speed with low losses. The relatively large size of these flow paths permits personnel access to either face of the $\mathrm{HX}$, for inspection and repair work.

The decision to select this major change in the configuration of the IRT was based in part on the successful use of a similar configuration in the smaller Boeing Research Aerodynamic Icing Tunnel (BRAIT), located in Seattle, Washington. ${ }^{7}$ In the BRAIT, however, the expanding and contracting turning vanes upstream and downstream of the flat $\mathrm{HX}$ were formed from closely-spaced, curved steel plates. For both aerodynamic and accessibility reasons, thick cambered airfoils were selected for the IRT turning vanes, in preference to the curved steel plates.

During the design of the steel structure of the new C-D leg, special attention was given to mitigating the effects of corrosion that had been a continuous problem with the original $1 / 4$-inch $(6.4-\mathrm{mm})$ thick plates forming the duct flow surfaces. The thickness of the steel plates forming the duct was increased by $1 / 16$ inch $(1.5 \mathrm{~mm})$ over the thickness required for strength and stiffness. With this corrosion allowance, the new floor plates are $3 / 8$ inch $(9.6 \mathrm{~mm})$ thick and the wall and ceiling plates are $5 / 16$ inch $(8.0 \mathrm{~mm})$ thick. In addition, the paint system was selected for maximum protection against corrosion, and consisted of a moisture-cure urethane paint containing a micaceous iron oxide (MIO) additive. This additive, in the form of flakes, provides toughness to the paint during the large temperature changes occurring during IRT operations.

The conceptual design phase also defined two upgrades to the fan motor subsystem. These included replacement of the electronic controls for the variablespeed motor and the installation of outlet guide vanes around the fan motor housing directly downstream of the fan blades. Figure 6 is a block diagram of the drive electrical system. It was determined that the maintenance problems with the drive were centered in the obsolete microcomputer. The other hardware in the system worked well, without any of the deficiencies described earlier. Therefore, bids were requested for the replacement of the microcomputer alone, with options to replace the entire system.

Earlier measurements of airspeed and flow angularity in the Vent Tower Section, downstream of the fan, showed that airspeed was highly variable across the entrance to Corner $C$. When the outflow of the fan was swirling in the direction of rotation, the two long fairings on the legs of the fan motor stand were found to concentrate the flow along the floor and near the inner wall, with relatively low airspeeds along the ceiling near the outer wall. Outlet guide vanes were selected as a means of removing the swirl and making the airspeed distribution more uniform as the flow enters Corner $C$ and the heat exchanger. This was expected to result in a more-uniform temperature distribution in the flow leaving the $\mathrm{HX}$.

The selected OGV design was that of a set of cambered airfoils placed radially outward from the fan motor housing at 24-deg intervals. As shown by the crosssections in Figure 7, each OGV has a uniform chord of $71.7 \mathrm{in.}(1,821 \mathrm{~mm})$ and a leading edge that is angled to the tunnel axis at approximately $45 \mathrm{deg}$ inboard (at the fan motor housing) and $20 \mathrm{deg}$ outboard (at the tunnel wall). ${ }^{8}$ While there are nominally 15 OGV positions, the leg fairings took two of these, and the one OGV 
between the leg fairings was eliminated as both unnecessary and interfering with personnel access to the fan blades. Therefore, only 12 OGV's were required. The trailing edge of one $\mathrm{OGV}$ was notched to permit opening of an access door in the fan housing.

To avoid any structural resonance excited by the passing of the 12 blades of the fan up to its maximum speed of $460 \mathrm{rpm}$, the fundamental natural frequency of the OGV's was required to be at least $100 \mathrm{~Hz}$.

\section{Preliminary and Final Design Phases}

On the basis of this series of in-house concept studies, approval was received to proceed with preliminary and final design. A design contract was awarded to Aero Systems Engineering, Inc. (St. Paul, Minnesota). ASE conducted additional concept studies, developed project design criteria, and produced final design drawings and specifications for the new C-D leg. 9. 18 Subcontractor specifications were also developed by ASE for the replacement $\mathrm{HX}$, the new corner turning vanes, and the fan outlet guide vanes. A basement was added under the C-D leg, which allows the tunnel floor to be well insulated with easier access to piping and cabling. Previously, there was only a crawl space under the uninsulated floor of the C-D leg.

Preliminary design of the replacement $\mathrm{HX}$ was performed by Cloudy+Britton, Inc. (Mountlake Terrace, Washington), with final design and fabrication by Frigid Coil/Imeco, Inc. (Santa Fe Springs, California). The two side-by-side HX units illustrated in Figure 4 were each fabricated in four identical modules, stacked vertically. Each module is $24.5 \mathrm{ft}$ wide, $6.56 \mathrm{ft}$ high, and $4.13 \mathrm{ft}$ thick in the flow direction ( $7.47 \mathrm{~m} \mathrm{x} 2.00 \mathrm{~m} \mathrm{x} 1.26 \mathrm{~m}$ ). R-134a coolant flows through 16 staggered rows of horizontal, Ushaped aluminum tubes 1.03 -in. in diameter. The tube rows are arranged in three separate zones in the flow direction (with 6,6 , and 4 rows per zone), each with its own supply and return headers and valves for temperature-balancing purposes. Vertical fins in each module are of aluminum and have a pitch of 0.667 in. $(16.9 \mathrm{~mm})$ in the upstream and middle zones and $0.50 \mathrm{in} .(12.7 \mathrm{~mm})$ in the downstream zone.

Table 3 contains a summary of the HX design-point parameters when it is operating dry and after four hours of frost accumulation. The design-point operating conditions are a test airspeed of $300 \mathrm{mph}(134 \mathrm{~m} / \mathrm{s})$ and a test temperature of $-1.4 \mathrm{~F}(-18.6 \mathrm{C})$.

Engineering Laboratory Design, Inc. (Lake City, Minnesota) created the structural designs of the composite airfoils for the new turning vanes and the OGV's, with stress analysis support from Jordan Engineering (Mill Valley, California). Each turning vane consists of three hollow segments stacked vertically. Figure 8(a) shows the design configuration of a middle-tier segment with integral flanges for bolting to the lower and upper tiers of segments. The upper end of each vane slides into a composite socket bolted to the tunnel ceiling, to accommodate differential thermal expansion and contraction. Each segment is fabricated in two pieces that are bonded together at its leading and trailing edges. Figure $8(\mathbf{b})$ illustrates the laminate structure of the vane walls, composed of a rigid foam core between layers of glass-fiber mat and woven roving bonded with vinyl ester resin. The structural design driver was the maximum allowable local panel deflection of less than the chord length/ 600 , or 0.17 in. $(4.4 \mathrm{~mm})$. With this composite wall construction, design deflections were limited to 0.06 in. $(2.1 \mathrm{~mm})$.

The air loading on the turning vanes is directed mainly outward along the comer diagonal. To carry two-thirds of this load, two horizontal tie plates of a glassreinforced composite are sandwiched between the vane flanges shown in Figure 8(a) and anchored to the inner tunnel walls. A shear connection between each vane and the tunnel floor and socket connections to the ceiling carry the other third of the airloads along the corner diagonal.

Figure 9(a) shows the structural configuration of the OGV's. The flange on the outboard end is bolted to the tunnel wall. The inboard end slides in a composite socket bolted to the fan motor housing, for thermal stress relief. Two internal webs are required for the structure to achieve the specified minimum natural frequency of $100 \mathrm{~Hz}$. The additional stiffening of carbon-fiber fabric in the laminate was also needed, as shown in Figure 9(b).

\section{Design Verification Phase with SMIRT}

The quantitative effects of the major modifications planned for the IRT were largely unknown at the start of this upgrade program. Changes such as widening the C-D leg, using fewer and larger turning vanes with novel expanding and contracting designs, adding OGV's to the fan, causing larger pressure losses through the $\mathrm{HX}$, and placing the inner and outer $\mathrm{HX}$ units in an offset position all introduced some level of technical risk. To reduce this risk and verify the design assumptions, flow quality tests were performed in a 1/10th-scale model of the IRT, designated as the SMIRT, in parallel with the design effort. ${ }^{11,12,13}$

Figure 10 shows the SMIRT with the two different configurations of the C-D leg that were tested in this program. Figure 10(a) is a view of the SMIRT in its initial configuration, modeling the original IRT loop. In the foreground is Corner $D$, with a mock-up of the original $\mathrm{W}$-shaped heat exchanger to the left. Under the 
safety shield in the rear is a scale-model fan that is driven by an air turbine to produce the $350-\mathrm{mph}$ $(156-\mathrm{m} / \mathrm{s})$ airspeed selected for the SMIRT tests. Figure $10(b)$ is a view of the SMIRT model of the new C-D leg, showing the new configurations of the turning vanes in Corners $C$ and $D$ and models of the inner and outer heat exchanger units. These HX models are commercially available units, and their streamwise thickness is somewhat larger than scale.

Instrumentation used to measure local airspeeds, flow angles, turbulence, and pressure in the SMIRT consisted of Pitot and hot-wire probes mounted on a remotely controlled traversing mechanism. Data samples were taken along multiple horizontal and vertical traverses at critical sections in the tunnel loop, from the fan outlet to the Test Section.

The first series of tests in the SMIRT were conducted to verify that flow defects measured in the SMIRT would quantitatively represent those in the IRT. Axial airspeed distributions measured across the SMIRT and IRT Vent Tower Sections were compared, and the flow distortions in each were found to very similar in both size and location. Figure 11(a) is a polar plot of the two airspeed distributions across the section, in which the view is downstream toward Corner C. ${ }^{11}$ Each data point represents axial airspeed measurements averaged over a 5-deg sector centered on the tunnel axis and then divided by the section-average airspeed. The sizes and positions of the IRT maximum and minimum airspeed ratios are both modeled almost exactly in the SMIRT, and the transitions between these extremes are closely represented.

For quantitative comparison, the coefficient of variability (COV) of the SMIRT airspeed distribution in Figure 11(a) is 41.3 percent, compared to the actual IRT COV of 36.6 percent, where the COV is the ratio of the standard deviation of the measurements divided by the average of the measurements.

The radial locations of the fairings on the North and South legs of the fan motor support stand are indicated in Figure 11(a) by the two inclined lines. Taking note of the direction of fan rotation, it can be seen that maximum airspeeds occur along the left side of the South leg, where the counter-clockwise swirl in the fan wake is blocked and would develop a higher pressure. Conversely, minimum airspeeds occur along the right side of the North leg, where swirl would develop lower pressure. These observations provided the rationale for installing OGV's immediately downstream of the fan. If swirl could be eliminated from the fan wake by the OGV's, the influence of the leg fairings would be minimized and the airspeed distribution through Comer $\mathrm{C}$ and into the $\mathrm{HX}$ would be made significantly more uniform.
This rationale was verified by SMIRT tests in which OGV's were simulated by five baffle plates placed around the fan motor housing. When the baffle length was extended downstream as far as the leg fairings (1.4 times the fan diameter), the COV of the downstream airspeed distribution was reduced from the 41.3 percent discussed earlier to the low value of 13.9 percent. ${ }^{11}$

During the preliminary design phase of the upgrades, when the geometry was defined for the new C-D leg, the replacement $\mathrm{HX}$, and the new turning vanes in Corners $\mathrm{C}$ and $\mathrm{D}$, the SMIRT was re-configured to model the future configuration of the IRT, as shown in Figure 10(b). Flow quality surveys were conducted across sections in the vent tower, at the inlet and outlet of the HX, in the wakes of the turning vanes in Comers $\mathrm{C}$ and $\mathrm{D}$, at the inlet to the spraybars, and in the middle of the Test Section. These measurements were the basis for projections of the flow quality improvements to be expected in the IRT. ${ }^{12}$

Figure 11(b) shows an example of the SMIRT flow quality projections compared with equivalent data from the original IRT. Shown here is the vertical distribution of axial airspeed in the Stilling Chamber. In the unmodified IRT the peak-to-valley variations in the "W" signature are as large as the average airspeed itself. By contrast, airspeed measurements made in the modified SMIRT at this same location project a range of only about 10 percent of the average airspeed.

Another example of the SMIRT test data is shown in Figure 5(b). The projected distribution of airspeeds exiting from the Corner D turning vanes is illustrated by the velocity vectors immediately downstream of vane $D-5 .{ }^{12}$ These vectors are derived from flow measurements made with a hot-wire probe moving horizontally across the section shown. It can be seen that each vane produces a definite wake. Local airspeeds are higher between vanes and lower directly downstream of vane trailing edges. However, most of these speed variations are removed as the flow passes through the contraction section of the IRT.

Table 4 contains a summary of flow quality parameters measured in the IRT before modification and projections from SMIRT test data for these same parameters after modification to the tunnel. A detailed comparison of these projections with actual flow quality measurements made in the modified IRT and a discussion of lessons learned from this modeling program is available. ${ }^{13}$ Flow quality projections from SMIRT data were in generally good agreement with the IRT data, and the SMIRT tests provided the required design verification for this upgrade program. 


\section{Construction Phase}

A request for bids to replace the electronic controls for the fan motor was released in late 1998. The vast majority of responses were for complete new systems, not just an upgrade of the electronic controls. The reasoning behind these broader responses was that interfacing a modem controller with an older electrical system would require significant modifications to the code in the controller, as well as modifications to the controller hardware.

The cost of replacing all electrical and electronic equipment feeding the drive motor was approximately five times that of replacing only the electronic controls. Not surprisingly, a contract solely for replacement of the original microprocessor was awarded to the company owning the original Varichron design, Alstom Drives and Controls, Inc. (Pittsburgh, Pennsylvania), which had the intimate knowledge of both the old and new controls necessary to interface these two systems.

The prime contract for demolishing the existing C-D leg, building the modified leg on new foundations and a basement, fabricating and installing the new turning vanes and OGV's, and installing the new $\mathrm{HX}$ with its piping system was awarded to the East-West Construction Company (Cleveland, Ohio) in July 1997. Principal subcontractors were the Frigid-Coil//meco Corporation, which fabricated the replacement heat exchanger and delivered it to the site, and Engineering Laboratory Design, Inc., which designed, fabricated, and installed the composite turning vanes in Corners $\mathrm{C}$ and D and the outlet guide vanes (OGV's) around the fan motor housing.

Preparation of shop drawings, ordering of materials and parts, and other work outside the tunnel (Phase 1) commenced in August 1997. Demolition and construction work (Phase 2) began on May 10, 1999. The tunnel was ready for re-activation tests on November 23, 1999, with completion of the contract work on April 28, 2000. The entire duration of construction was 1,003 days. Figures 12 to 16 are views of the demolition and construction work, and the installation of the HX modules.

Figures 17 to 19 show the installation of the new turning vanes. In Figures 17 and 18, the segmented construction of the turning vanes, the horizontal tie plates between bolted flanges, and the large sizes of the flow passages between vanes can be seen. In each corner, one lower segment of a turning vane was designed to be removable, to provide access to each side of the HX for a powered lift vehicle. The removable segment in Corner D can be seen in Figure 18 , at the bottom of the seventh vane from the left. Figure 19 is a close-up view of the outer end of a tie plate in Comer C. The extruded fiberglass tie plate is reinforced with steel plates that bear against wall brackets, to help carry streamwise airloads on the vane array.

Figure 20 illustrates the relatively large size of the fan OGV's and their installation around the motor housing. The view is upwind. Several of the wood fan blades can be seen in the background, with their leading edges covered by protective rubber boots. Figure $\mathbf{2 1}$ shows the socket connections to the motor housing that provide for differential thermal expansion and contraction in the radial direction. Also shown in this figure is the OGV with its trailing edge cut out to allow an access door to open in the motor housing.

\section{Reactivation Phase}

A comprehensive series of reactivation tests was begun in December 1999, near the end of the construction phase of the upgrade program. ${ }^{14}$ The most important of these reactivation tests are listed in Table 2 , together with their objectives. A detailed discussion of the results of these tests and some of the lessons leamed from them is available. ${ }^{15}$ A brief overview will be given here.

Reactivation of the IRT began with static and lowspeed checkouts of the new electronic controls for the fan motor. Motor speed was then gradually increased to its maximum allowable level of $460 \mathrm{rpm}$ to verify safe and stable operation of the motor controls and the aero-structural integrity of components such as the fan blades, the new turning vanes, and the new OGV's. Strain gages on the fan blades and accelerometers on the turning vanes and OGV's were used to monitor stresses and vibrations, which were all below allowable limits.

Figure 22 shows a comparison of the test airspeeds achievable before and after tunnel modifications, with an empty test section and dry, ambient air temperature conditions. It can be seen from this chart that the maximum airspeed attainable in the IRT has decreased from its historic high of $420 \mathrm{mph}(188 \mathrm{~m} / \mathrm{s})$ measured during the 1994 qualification of new fan blades to approximately $390 \mathrm{mph}(174 \mathrm{~m} / \mathrm{s})$ today. This decrease is attributed to an approximately 70 percent increase in the drag losses across the flat HX compared with the original W-shaped $\mathrm{HX}$, and to more drag loss than expected at the OGV's.

In Figure 23, pressure drops measured across the new HX are compared with design pressure drops. The range labeled "preliminary design" is a direct application of pressure drops measured across the original $\mathrm{W}$-shaped heat exchanger, where heavy frost doubled the pressure drop. ${ }^{16}$ In the final design of the replacement HX, however, frost was expected to cause 
only a small increase in the pressure drop. This is shown by the two final design points at the bottom of the range, which represent operation at a test airspeed of $300 \mathrm{mph}$ ( 134 meters per second). Pressure losses across the new $\mathrm{HX}$ with or without frost were expected to be about the same as those with the original HX in a dry condition. Examination of the actual pressure drops measured across the new $\mathrm{HX}$ with and without frost shows that the minor effect of frost was correctly predicted. While the pressure losses without frost at the design point are about 70 percent higher than predicted, losses for the frosted condition are still lower than those for the original HX. Therefore, these additional drag losses at the $\mathrm{HX}$ are not expected to significantly affect tunnel operations during icing tests at moderate airspeeds and with test section blockage.

Next, the new HX was brought on-line to verify the function of valves and controls. The coolant flows to each of the eight HX modules and their 24 controllable zones were then balanced to minimize temperature variations downstream. During these tests it was determined that the 24 remotely controlled valves in the system (one for each zone) were not necessary for obtaining a uniform air temperature output. Manual valves controlling the flow to each zone are sufficient for thermal balancing of the HX. All remotely controlled valves were placed in a full-open condition pending their removal during a future shutdown period. This will eliminate the drop in coolant pressure at each valve and increase the effectiveness of the HX.

After both the aerodynamic and thermal subsystems of the IRT were determined by an independent review committee to be operating properly and safely, an Integrated System Test was conducted successfully that simulated a typical icing test program during a night of operation of the IRT.

Figure 24 illustrates the improvements obtained in air temperature uniformity with the replacement $\mathrm{HX}$. In this chart, the standard deviation of air temperature measured downstream of the $\mathrm{HX}$, at the entrance to Corner D, is plotted versus the test airspeed. Deviations are approximately $0.6 \mathrm{~F}(0.3 \mathrm{C})$ less with the new HX than with the old, which is a reduction of approximately 50 percent at a test airspeed of $200 \mathrm{mph}$ $(94 \mathrm{~m} / \mathrm{s})$.

Testing of the current low-temperature capability of the IRT was begun, but has now been postponed until the remotely controlled coolant valves have been removed, because this should improve the results of the tests. Figure 25 shows the preliminary low-temperature data obtained with the valves in place. In this chart the minimum static temperature attainable is plotted versus the test airspeed. The FAA requirement of $-22 \mathrm{~F}$ $(-30 \mathrm{C})$ is shown, together with the design requirement for the new HX (Option E) and a more ambitious design goal (Option F). These options represent upper and lower bounds on low-temperature test data measured in 1995 with the original W-shaped HX in operation. The test data shown in the figure are at an airspeed of $350 \mathrm{mph}(156 \mathrm{~m} / \mathrm{s})$ with all pressure regulating valves in place and with and without an icing spray.

A quantitative measure of the cooling performance of a heat exchanger is its thermal effectiveness, defined as the ratio of the drop in air temperature across the $\mathrm{HX}$ to the difference between the inlet air temperature and the internal coolant temperature. In Figure 26 some preliminary data on the thermal effectiveness of the new $\mathrm{HX}$ are compared with performance data for the original HX. As expected, the higher face (inlet) airspeeds in the new $\mathrm{HX}$ reduce its thermal effectiveness somewhat, compared to the W-shaped HX with its much lower face speed for the same test airspeed. However, these preliminary data still indicate that the performance of the new $\mathrm{HX}$ under icing test conditions will meet design requirements and may be close to the design goal shown in Figure 25 after the 24 remotely control valves are removed.

Calibration of the uniformity, droplet size, and liquid water content of the icing cloud was a major element of the activation program, consuming almost 60 percent of the activation operating time. Because of the major changes made to the quality of the airflow entering the spraybar section of the tunnel, hundreds of spray nozzles were repositioned to obtain the maximum uniformity of ice accretion in the Test Section. ${ }^{17}$ Icing uniformity was assessed by measuring the thickness of ice deposited on a grid of steel bars with a spacing size of 6 in. by 6 in. (152 $\mathrm{mm} \times 152 \mathrm{~mm})$. Figure 27 is a layout of this uniformity grid and the nomenclature used to record ice thickness data. Figure 28 is a typical contour plot of the variability of ice accretion across the Test Section, expressed as deviations of local thickness from the average thickness.

A side benefit of the replacement heat exchanger project was realized when, for the first time in the IRT, the two different types of water spray nozzles (Standard and Mod-1) were installed side-by-side. The tunnel downtime required for the 1999 upgrade program also provided time for the installation of this dual spray nozzle system. With both nozzle sets installed, the IRT spray system can now cover more of the icing requirements in the Federal Aviation Regulation (FAR) Part 25, Appendix $\mathrm{C}$ without a time-consuming nozzle change-out.

Improving the quality of the airflow entering the spraybars has had a small negative effect on the uniformity of the icing cloud. The higher turbulence 
and angularity produced by the original $\mathrm{W}$-shaped heat exchanger actually helped to mix the water droplets into a more uniform cloud. ' The current upgrades have reduced the turbulence and flow angularity, and the water droplets from each spray nozzle tend to remain in a narrow stream rather than mix with droplets from adjacent nozzles. For this reason, icing uniformity appears to have degraded somewhat. ${ }^{17}$

Aero-thermal calibration of the Test Section was performed, following standard procedures used earlier in the IRT and other wind tunnels at the Glenn Research Center. Airspeeds, flow angles, turbulence, and temperatures were measured at grid points spanning the middle section of the Test Section, to produce statistical data like that shown in Figures 29 and 30. Detailed descriptions of these and similar calibration charts for the modified IRT are available. ${ }^{18}$ 19

The final step in the activation program was a verification that current ice shapes agree with those produced in the past in the IRT, for a standardized airfoil model tested under standardized conditions of airspeed, temperature, time, and liquid-water content in the icing cloud. Current shapes of rime ice and glaze ice were found to match previous shapes within allowable limits. ${ }^{20}$

\section{Operating Time to Date}

The IRT was operated for a total of 571.1 hours during the activation test program, without incident. As of November 17,2000 , the total operating time on the modified IRT was 978 hours.

\section{Conclusions}

1. All of the objectives of the 1999 IRT upgrade program were achieved.

2. Some reduction in the performance of the IRT was measured during the activation test program. The maximum attainable airspeed was reduced by about 7 percent under dry operating conditions, because of the higher drag losses of the replacement heat exchanger and the fan outlet guide vanes. However, drag of the new heat exchanger is relatively insensitive to frost accumulation, so airspeeds under icing conditions are affected less than under dry conditions.

3. Uniformity of icing in the test section was reduced somewhat because of less mixing of the water droplets within the icing cloud as flow turbulence and angularity were reduced by the upgrades.

4. Remote control of individual cooling zones in the replacement heat exchanger is not required for temperature uniformity downstream. Remote control pressure regulating valves can be removed from the system, reducing the coolant pressure drop through the heat exchanger and increasing maximum coolant flow rates.

5. Preliminary test data indicate that the lowtemperature performance limit of the upgraded IRT will meet the design goal under dry conditions and the design requirement under icing conditions, exceeding FAA requirements. The complete range of low-temperature limits is not yet defined as a function of airspeed, blockage, and spray conditions. The planned facility performance test has been postponed until the remotely controlled valves in the heat exchanger are removed (see Conclusion 3 ).

6. Operation of the modified IRT for a total of 978 hours without incident (as of November 17, 2000) indicates that start-up problems have been successfully addressed and that the tunnel is ready for normal research operations.

\section{References}

1. Soeder, R. H.; Sheldon, D. W; Andracchio, C. R.; Ide, R. F.; Spera, D. A.; and Lalli, N. M.: NASA Lewis Icing Research Tunnel User Manual, NASA TM 107159. NASA Lewis Research Center, 1996.

2. Irvine, T. B., Oldenburg, J. R., and Sheldon, D. W.: New Icing Cloud Simulation System at the NASA Glenn Research Center Icing Research Tunnel, NASA/TM-1999-208891 (also AIAA98-0143). NASA Glen Research Center, 1999.

3. Arrington, E. A.; Pickett, M. T.; Sheldon, D. W.: Flow Quality Studies of the NASA Lewis Research Center Icing Research Tunnel Circuit, NASA TM 106545. NASA Lewis Research Center, 1994.

4. Arrington, E. A.; Gonsalez, J. C.; Kee-Bowling, B. K.: Flow Quality Studies of the NASA Lewis Research Center Icing Research Tunnel Circuit (1995 Tests), NASA TM 107479. NASA Lewis Research Center, 1998.

5. Spera, D. A.: Comparison of Concepts for Improved IRT Heat Exchanger, and Analysis of IRT Heat Exchanger Test Data from NASA TM 100116, Sverdrup Corporation (unpublished). NASA Lewis Research Center, August 1994.

6. Sanz, J. M.: Aerodynamic Design of New Expanding and Contracting Turning Vanes for the NASA Lewis Icing Research Tunnel 
(unpublished). NASA Lewis Research Center, October 1996.

7. Chintamani, S., Delcarpio, D., and Langmeyer, G.: Development of Boeing Research Aerodynamic Icing Tunnel Circuit. AGARD paper at "Symposium on Aerodynamics of Wind Tunnel Circuits and Their Components", Moscow, 1996. North Atlantic Treaty Organization, Neuilly sur Seine, France 1996.

8. Schmidt, J. F.: Aerodynamic Design of New Fan Outlet Guide Vanes for the NASA Lewis Icing Research Tunnel, NYMA Corporation (unpublished). NASA Lewis Research Center, October 1996.

9. Anonymous: NASA LeRC IRT Replacement Heat Exchanger Concept Study, NASA LeRC Contract No. NAS3-27613, Phase 2, Special Study Report 2, Aero Systems Engineering, Inc. (unpublished). NASA Lewis Research Center, 1996.

10. Anonymous: Icing Research Tunnel Building No. 11 Heat Exchanger Replacement, NASA LeRC Contract No. NAS3-27613, Final Report, Vols. 1 and 2, Aero Systems Engineering, Inc. (unpublished). NASA Glen Research Center, 1999.

11. Canacci, V. A.; Gonsalez, J. C.; Spera, D. A.; and Weaver, H. L.: Scale Model Icing Research Tunnel Validation Studies, AIAA-98-0706. NASA Lewis Research Center 1998.

12. Canacci, V. A.; Spera, D. A.; and Gonsalez, J. C.: Flow Quality Studies of the Scale Model Icing Research Tunnel and Projections to the Full-Scale Modified IRT, AIAA-99-0307. NASA Lewis Research Center, 1999.

13. Canacci, V. A., Gonsalez, J. C., and Spera, D. A.: Use of a Scale Model Tunnel in the Design of Modifications to the NASA-Glenn Icing Research Tunnel, AIAA-2001-0230. NASAGlenn Research Center, 2001.

14. Sheldon, D. W., and Spera, D. A.: Activation Plan for the Modified GRC Icing Research Tunnel (IRT) (unpublished). NASA Glenn Research Center, August 1999.

15. Sheldon, D. W., Andracchio, C. R., Krivanek, T. M., Spera, D. A., and Austinson, T. A.: Lessons Learned and Results from the Construction Phase and Qualification Testing of the Icing Research Tunnel Upgrades, AIAA-2001-0231. NASA-Glenn Research Center, 2001.

16. Olsen, W.; Van Fossen, J.; and Nussle, R: Measured Performance of the Heat Exchanger in the NASA Icing Research Tunnel Under Severe Icing and Dry Air Conditions, NASA TM 100116. NASA Lewis Research Center, 1987.

17. Ide, R. F.: Icing Cloud Calibration of the NASA Glenn Icing Research Tunnel, AIAA-2001-0234. NASA Glenn Research Center, 2001.

18. Gonsalez, J. C., Arrington, E. A., and Curry, M. III: Flow Quality Surveys in the NASA Glenn Icing Research Tunnel (2000 Tests), AIAA2001-0232. NASA Glenn Research Center, 2001 .

19. Gonsalez, J. C., Arrington, E. A., and Curry, M. III: Aero-Thermal Calibration of the NASA Glenn Icing Research Tunnel (2000 Tests), AIAA-2001-0233. NASA Glenn Research Center, 2001.

20. Van Zante, J.: Correlation of Current and Historical Ice Accretion Shapes on an NACA 0012 Airfoil in the NASA Glenn Icing Research Tunnel (unpublished). NASA Glenn Research Center, July 2000. 
Table 1. - Major Upgrades to the IRT

\begin{tabular}{|c|l|}
\hline Year & \multicolumn{1}{|c|}{ Upgrade } \\
\hline 1999 & $\begin{array}{l}\text { Replace motor control electronics. Replace heat exchanger. Replace C-D leg, adding } \\
\text { basement. Replace C- and D-comer turning vanes. Add fan outlet guide vanes. }\end{array}$ \\
\hline $1996-7$ & $\begin{array}{l}\text { Install new spraybar subsystem and upgrade controls, increasing number of bars from 8 to 10. } \\
\text { Icing cloud size and uniformity increased approximately 100 percent. Time required to } \\
\text { stabilize the icing cloud decreased 90 percent. Install cold room 3D laser scanner for } \\
\text { recording ice shapes. }\end{array}$ \\
\hline $1993-4$ & $\begin{array}{l}\text { Install new insulated siding on east half of tunnel (2-in. foam core with steel face sheets). } \\
\text { Install new wood fan blades with increased pitch, increasing max test airspeed from 305 mph } \\
\text { to 420 mph. Increase number of spraybars, from 6 to 8. }\end{array}$ \\
\hline 1992 & $\begin{array}{l}\text { Install new insulated siding on West half of tunnel (2-in. foam core with steel face sheets). } \\
\text { Install 5-component external force balance. Install video cameras and test section lighting to } \\
\text { monitor ice accretion. }\end{array}$ \\
\hline 1986 & $\begin{array}{l}\text { Replace fan drive motor, increasing power to 5,000 hp. Upgrade controls to digital } \\
\text { Varichron system. Upgrade other tunnel and refrigeration controls from analog to digital. } \\
\text { Fabricate spare set of wood fan blades. }\end{array}$ \\
\hline
\end{tabular}


Table 2. - Summary of Phases of IRT 1999 Upgrade Program

\begin{tabular}{|c|c|c|c|c|}
\hline $\begin{array}{l}\text { Program } \\
\text { Phase }\end{array}$ & Scope of Work & Dates & $\begin{array}{l}\text { Performing } \\
\text { Organization }\end{array}$ & $\begin{array}{c}\text { Contract } \\
\text { cost }\end{array}$ \\
\hline \multirow[t]{5}{*}{ Design } & $\begin{array}{l}\text { Conceptual design of HX configuration and } \\
\text { layout of new C-D leg }\end{array}$ & $\begin{array}{l}1994 \text { to } \\
1996\end{array}$ & $\begin{array}{l}\text { In-house: Sverdrup, } \\
\text { NYMA and NASA }\end{array}$ & NA \\
\hline & $\begin{array}{l}\text { Aerodynamic design of new C- and D-corner } \\
\text { turning vanes and OGV's }\end{array}$ & $10 / 96$ & $\begin{array}{c}\text { In-house: NASA and } \\
\text { NYMA }\end{array}$ & NA \\
\hline & $\begin{array}{l}\text { Concept studies, preliminary and final designs of } \\
\text { C-D leg, and HX specifications }\end{array}$ & $\begin{array}{l}1996 \text { to } \\
1999\end{array}$ & $\begin{array}{c}\text { Aero Systems } \\
\text { Engineering }\end{array}$ & \multirow[t]{3}{*}{$\$ 715 \mathrm{~K}$} \\
\hline & Preliminary design of replacement $\mathrm{HX}$ & 1996 & $\begin{array}{c}\text { Cloudy + Britton } \\
\text { (ASE subcontractor) }\end{array}$ & \\
\hline & $\begin{array}{l}\text { Preliminary structural design of new turning } \\
\text { vanes and OGV's }\end{array}$ & 1996 & $\begin{array}{l}\text { Engineering Laboratory } \\
\text { Designs (ASE subcontr.) }\end{array}$ & \\
\hline \multirow{2}{*}{$\begin{array}{c}\text { Design } \\
\text { Verification } \\
\text { with SMIRT }\end{array}$} & $\begin{array}{l}1 / 10 \text { th scale model of original IRT: } \\
\text { Verify correlation with IRT flow quality data }\end{array}$ & $\begin{array}{l}1996 \text { to } \\
1997\end{array}$ & $\begin{array}{c}\text { In-house: NYMA and } \\
\text { NASA }\end{array}$ & NA \\
\hline & $\begin{array}{c}\text { 1/10 th scale model of modified IRT: } \\
\text { Estimate level of flow quality improvements to } \\
\text { be obtained in IRT }\end{array}$ & 1998 & In-house: NYMA & NA \\
\hline \multirow[t]{5}{*}{ Construction } & $\begin{array}{l}\text { Design, fabrication, and installation of } \\
\text { replacement electronic controls for fan motor }\end{array}$ & $\begin{array}{l}9 / 99 \text { to } \\
12 / 99\end{array}$ & $\begin{array}{l}\text { Alstom Drives and } \\
\text { Controls }\end{array}$ & $\$ 190 \mathrm{~K}$ \\
\hline & $\begin{array}{l}\text { Abatement of lead paint in cutting/welding areas, } \\
\text { around fan motor housing, and remaining areas of } \\
\text { tunnel }\end{array}$ & $5 / 99$ & & $\$ 210 \mathrm{~K}$ \\
\hline & $\begin{array}{c}\text { Demolition of old C-D leg and construction of } \\
\text { new leg with new HX and airfoils }\end{array}$ & $\begin{array}{c}5 / 99 \text { to } \\
4 / 00\end{array}$ & $\begin{array}{c}\text { East-West Construction } \\
\text { (Prime contractor) }\end{array}$ & \multirow{3}{*}{$\begin{array}{c}\$ 5.3 \mathrm{M} \\
(\$ 0.9 \mathrm{M}) \\
(\$ 0.4 \mathrm{M})\end{array}$} \\
\hline & $\begin{array}{l}\text { Design and fabrication of } \mathrm{HX} \\
\text { And delivery to site }\end{array}$ & & $\begin{array}{l}\text { Frigid Coil//meco } \\
\text { (E-W subcontractor) }\end{array}$ & \\
\hline & $\begin{array}{l}\text { Structural design, fabrication, and installation of } \\
\text { composite turning vanes and OGV's }\end{array}$ & & $\begin{array}{c}\text { Engineering Laboratory } \\
\text { Designs } \\
\text { (E-W subcontractor) }\end{array}$ & \\
\hline Reactivation & $\begin{array}{l}\text { Checkout electronic controls for fan motor } \\
\text { Verify aero-structural integrity of fan, new } \\
\text { turning vanes, and OGV's } \\
\text { Verify HX stability and performance } \\
\text { Conduct Integrated System Test to verify } \\
\text { combined operation of all subsystems } \\
\text { Conduct Facility Performance Test to measure } \\
\text { operating envelope of airspeed and lowest } \\
\text { temperature, with and without icing and Test } \\
\text { Section blockage (postponed) } \\
\text { Reposition spray nozzles for maximum } \\
\text { uniformity in icing across Test Section } \\
\text { Calibrate distributions of airspeed and } \\
\text { temperature across Test Section } \\
\text { Verify correlation of current ice shapes with } \\
\text { historical ice shapes }\end{array}$ & $\begin{array}{c}12 / 99- \\
5 / 00\end{array}$ & $\begin{array}{l}\text { In-house: NASA and } \\
\text { Dynacs }\end{array}$ & NA \\
\hline
\end{tabular}


Table 3. - Heat Exchanger Design-Point Parameters

\begin{tabular}{|c|c|c|c|}
\hline Test Conditions & \multicolumn{3}{|c|}{ Design Data } \\
\hline Airspeed in Test Section (mph) & \multicolumn{3}{|c|}{300} \\
\hline Air temperature entering Corner $\mathrm{D}(\mathrm{F})$ & \multicolumn{3}{|c|}{-1.4} \\
\hline \multicolumn{4}{|l|}{ Modules (Coils) } \\
\hline Number & \multicolumn{3}{|c|}{8} \\
\hline Approximate weight (lb) & \multicolumn{3}{|c|}{7,145} \\
\hline Refrigerant & \multicolumn{3}{|c|}{$\mathrm{R}-134 \mathrm{a}$} \\
\hline Cooling capacity per module (ton) & \multicolumn{3}{|c|}{208.2} \\
\hline Cooling capacity of heat exchanger (ton) & \multicolumn{3}{|c|}{$1,665.8$} \\
\hline Coil height & \multicolumn{3}{|c|}{78.375} \\
\hline Fin height (in.) & \multicolumn{3}{|c|}{77.5} \\
\hline Finned length of coil (in.) & \multicolumn{3}{|c|}{294.0} \\
\hline Tube sheet depth (in.) & \multicolumn{3}{|c|}{51.0} \\
\hline Top and bottom aluminum plate thickness (in.) & \multicolumn{3}{|c|}{0.375} \\
\hline Face area (sq. ft) & \multicolumn{3}{|c|}{158.23} \\
\hline Inlet connections (in.) & \multicolumn{3}{|c|}{1 at $2.0 ; 2$ at 1.5} \\
\hline Outlet connections (in.) & \multicolumn{3}{|c|}{2 at $6.0 ; 1$ at 5.0} \\
\hline Air side of HX & Upstream & Middle & Downstream \\
\hline Number of rows of coolant tubes & 6 & 6 & 4 \\
\hline Fins per inch of tube length & 1.5 & 1.5 & 2.0 \\
\hline Number of coolant passes per row & 2 & 2 & 2 \\
\hline Total cooling surface area (sq. ft) & 6,381 & 6,381 & 5,385 \\
\hline Total air mass flow $(\mathrm{lbm} / \mathrm{s})$ & 1,843 & 1,843 & 1,843 \\
\hline Air mass flow per module $(\mathrm{lbm} / \mathrm{s})$ & 230.4 & 230.4 & 230.4 \\
\hline Relative humidity (\%) & 45.0 & 59.7 & 72.6 \\
\hline Inlet dry bulb temperature $(\mathrm{F})$ & 11.00 & 5.28 & 1.08 \\
\hline Air density (lbm/cu. ft) & 0.083 & 0.084 & 0.085 \\
\hline Air volume flow per module (cu. $\mathrm{ft} / \mathrm{m}$ ) & 166,357 & 164,335 & 162,847 \\
\hline Face airspeed $(\mathrm{ft} / \mathrm{m})$ & 1,051 & 1,039 & 1,029 \\
\hline Condensate precipitation rate $(\mathrm{lb} / \mathrm{h})$ & 0.00 & 11.94 & 13.63 \\
\hline Condensate accumulation in $4 \mathrm{hr}(\mathrm{lb})$ & 0.0 & 47.8 & 54.5 \\
\hline Avg. frost thickness in $4 \mathrm{hr}$, at $7 \mathrm{lb} / \mathrm{cu}$. $\mathrm{ft}$ (in.) & 0.0000 & 0.0128 & 0.0174 \\
\hline Pressure drop across zone: No frost (in. $\mathrm{H} 2 \mathrm{O}$ ) & 0.31 & 0.31 & 0.28 \\
\hline Pressure drop across zone: 4-h frost (in. $\mathrm{H} 2 \mathrm{O}$ ) & 0.31 & 0.36 & 0.36 \\
\hline Outlet dry bulb temperature $(\mathrm{F})$ & 5.28 & 1.08 & -1.4 \\
\hline \multicolumn{4}{|l|}{ Refrigerant side of $\mathrm{HX}$} \\
\hline Evaporator temperature $(\mathrm{F})$ & -18.0 & -18.0 & -18.0 \\
\hline Refrigerant flow (gal/m) & 21.4 & 17.7 & 11.8 \\
\hline Refrigerant flow (lb/m) & 243.35 & 207.70 & 138.47 \\
\hline Refrigerant flow rate & $1.20: 1$ & $1.37: 1$ & $1.53: 1$ \\
\hline Feed type & LRT & LRT & LRT \\
\hline Avg. circuit pressure drop (psi) & 0.460 & 0.270 & 0.220 \\
\hline Avg. circuit temperature drop (F) & 1.298 & 0.762 & 0.621 \\
\hline Cooling capacity (ton) & 95.1 & 70.7 & 42.5 \\
\hline
\end{tabular}


Table 4. - Changes in Average Flow Quality Parameters from Baseline to Modified IRT, Estimated from SMIRT Test Data

\begin{tabular}{|c|c|c|c|c|c|c|c|c|c|}
\hline \multirow[t]{2}{*}{$\begin{array}{l}\text { Station } \\
\text { no. }\end{array}$} & \multirow[t]{2}{*}{$\begin{array}{l}\text { Section } \\
\text { name }\end{array}$} & \multicolumn{2}{|c|}{$\begin{array}{l}\text { Variation in axial } \\
\text { airspeed, } \\
\text { COV } \\
\text { (percent) }\end{array}$} & \multicolumn{2}{|c|}{$\begin{array}{c}\text { Axial turbulence } \\
\text { intensity, } \\
u^{\prime} / U \\
\text { (percent) }\end{array}$} & \multicolumn{2}{|c|}{$\begin{array}{c}\text { STD of pitch } \\
\text { flow angle, } \\
d \alpha \\
\text { (deg) }\end{array}$} & \multicolumn{2}{|c|}{$\begin{array}{c}\text { STD of yaw } \\
\text { flow angle, } \\
d \beta \\
\text { (deg) }\end{array}$} \\
\hline & & $\begin{array}{l}\text { Actual: } \\
\text { Baseline } \\
\text { IRT }\end{array}$ & $\begin{array}{l}\text { Est.: } \\
\text { Modified } \\
\text { IRT }\end{array}$ & $\begin{array}{l}\text { Actual: } \\
\text { Baseline } \\
\text { IRT }\end{array}$ & $\begin{array}{l}\text { Est.: } \\
\text { Modified } \\
\text { IRT }\end{array}$ & $\begin{array}{l}\text { Actual: } \\
\text { Baseline } \\
\text { IRT }\end{array}$ & $\begin{array}{l}\text { Est.: } \\
\text { Modified } \\
\text { IRT }\end{array}$ & $\begin{array}{l}\text { Actual: } \\
\text { Baseline } \\
\text { IRT }\end{array}$ & $\begin{array}{l}\text { Est.: } \\
\text { Modified } \\
\text { IRT }\end{array}$ \\
\hline 2 & $\begin{array}{l}\text { Vent tower: } \\
\text { C-corner inlet }\end{array}$ & 36.6 & 13.9 & 23.4 & 21.5 & 6.4 & 1.6 & 5.3 & 1.7 \\
\hline 3 & $\mathrm{HX}$ inlet & 26.0 & 14.1 & 15.4 & 18.8 & 4.8 & 1.9 & 2.0 & 4.6 \\
\hline 4 & HX outlet & 44.5 & 7.0 & 29.0 & 9.0 & 5.1 & 0.6 & 3.6 & 0.6 \\
\hline 5 & $\begin{array}{c}\text { Stilling chamber: } \\
\text { Spraybar inlet }\end{array}$ & 21.5 & 5.2 & 8.4 & 3.7 & 1.0 & 0.8 & 3.5 & 1.4 \\
\hline $\begin{array}{c}6 \\
\text { (a) }\end{array}$ & $\begin{array}{c}\text { Test mid-section: } \\
6 \text { - } \mathrm{ft} \times 9 \text {-ft zone }\end{array}$ & 0.4 & 0.2 & $\cdots$ & 0.4 & 0.7 & 0.3 & 0.7 & 0.2 \\
\hline $\begin{array}{l}6^{\prime} \\
\text { (a) }\end{array}$ & $\begin{array}{c}\text { Test mid-section } \\
4 \text { - } \mathrm{ft} \times 5 \text {-ft zone }\end{array}$ & 0.2 & 0.02 & 0.6 & 0.3 & 0.7 & 0.3 & 0.5 & 0.2 \\
\hline
\end{tabular}

(a) Estimates without effects of spraybars; no spraybar model in SMIRT 
()$=$ No. of operating months; all others are 12 months

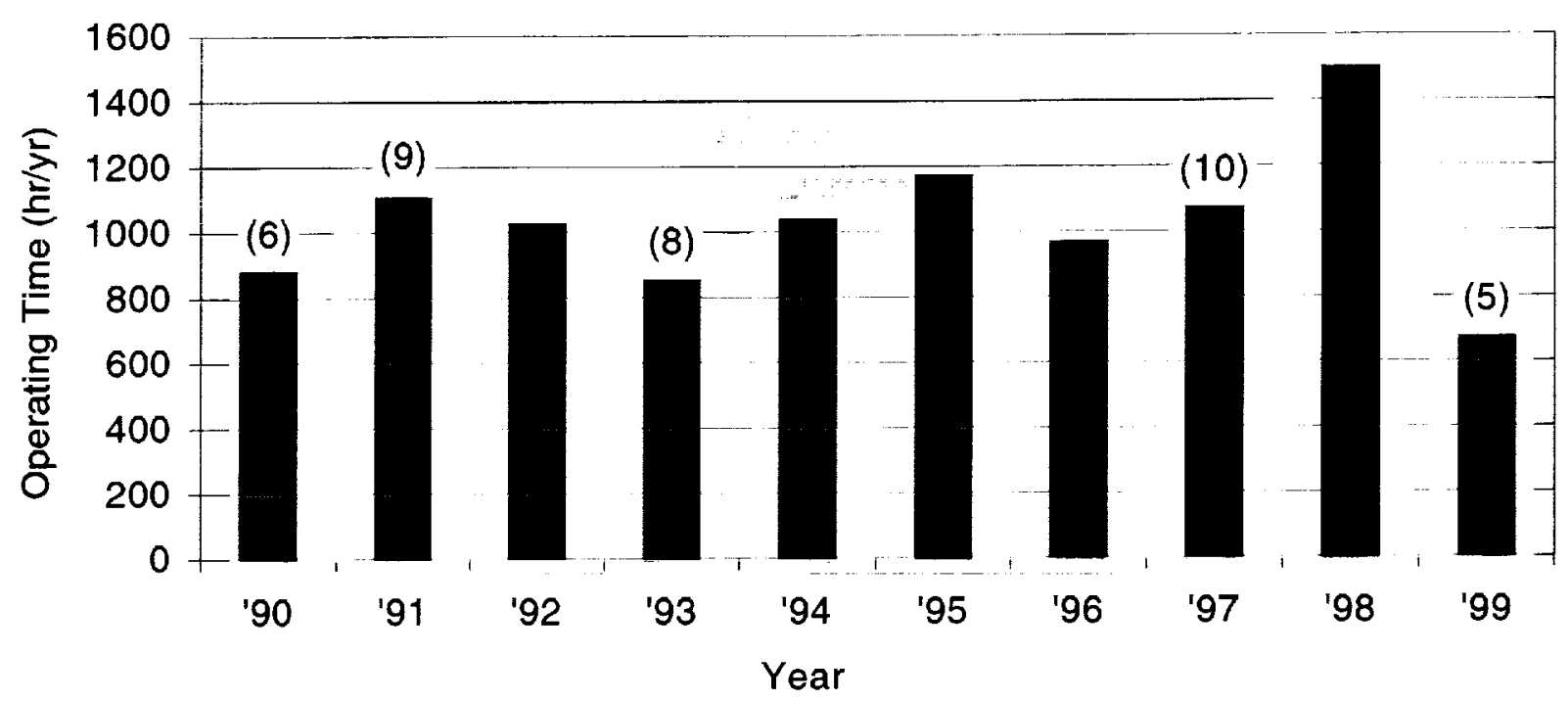

Figure 1. Annual running times in the 6'x 9' Icing Research Tunnel (IRT) since 1990.

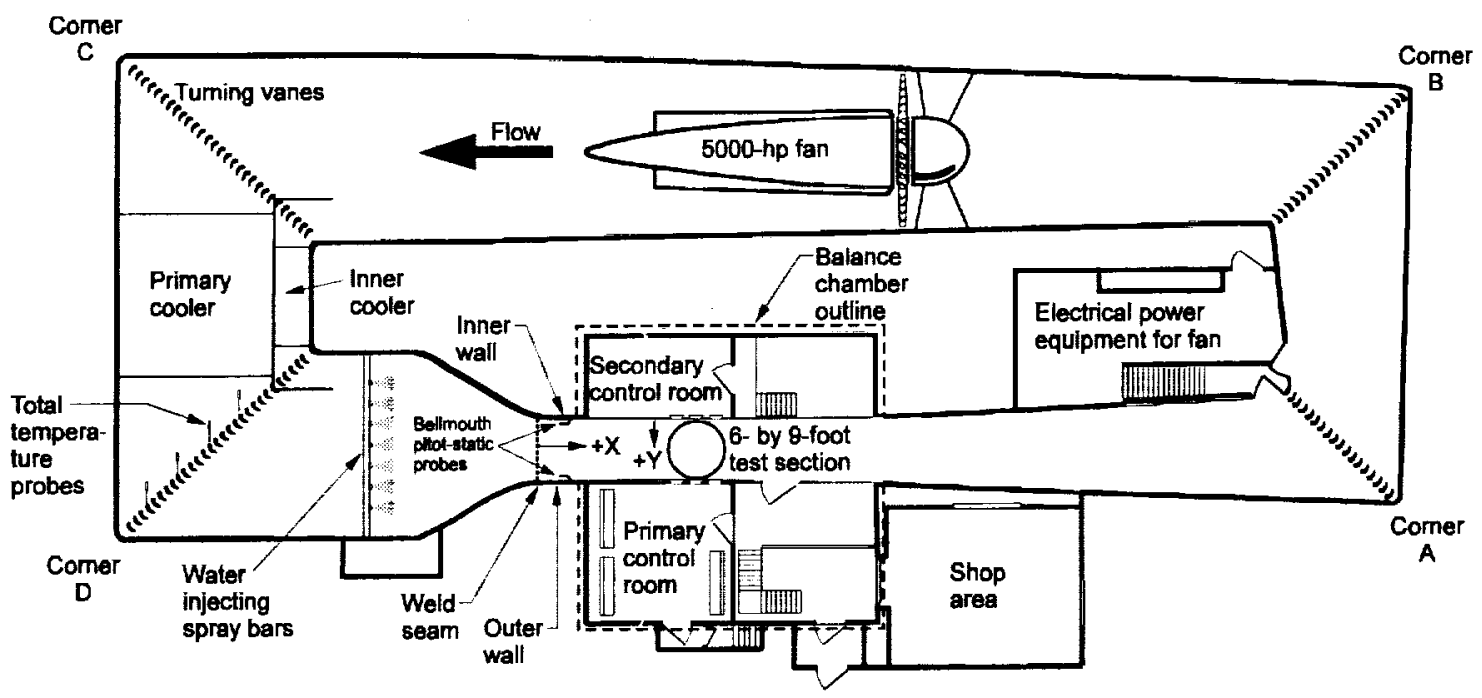

(a) Plan view of the tunnel loop.

Figure 2. Loop configuration of the IRT before the 1999 modifications. 


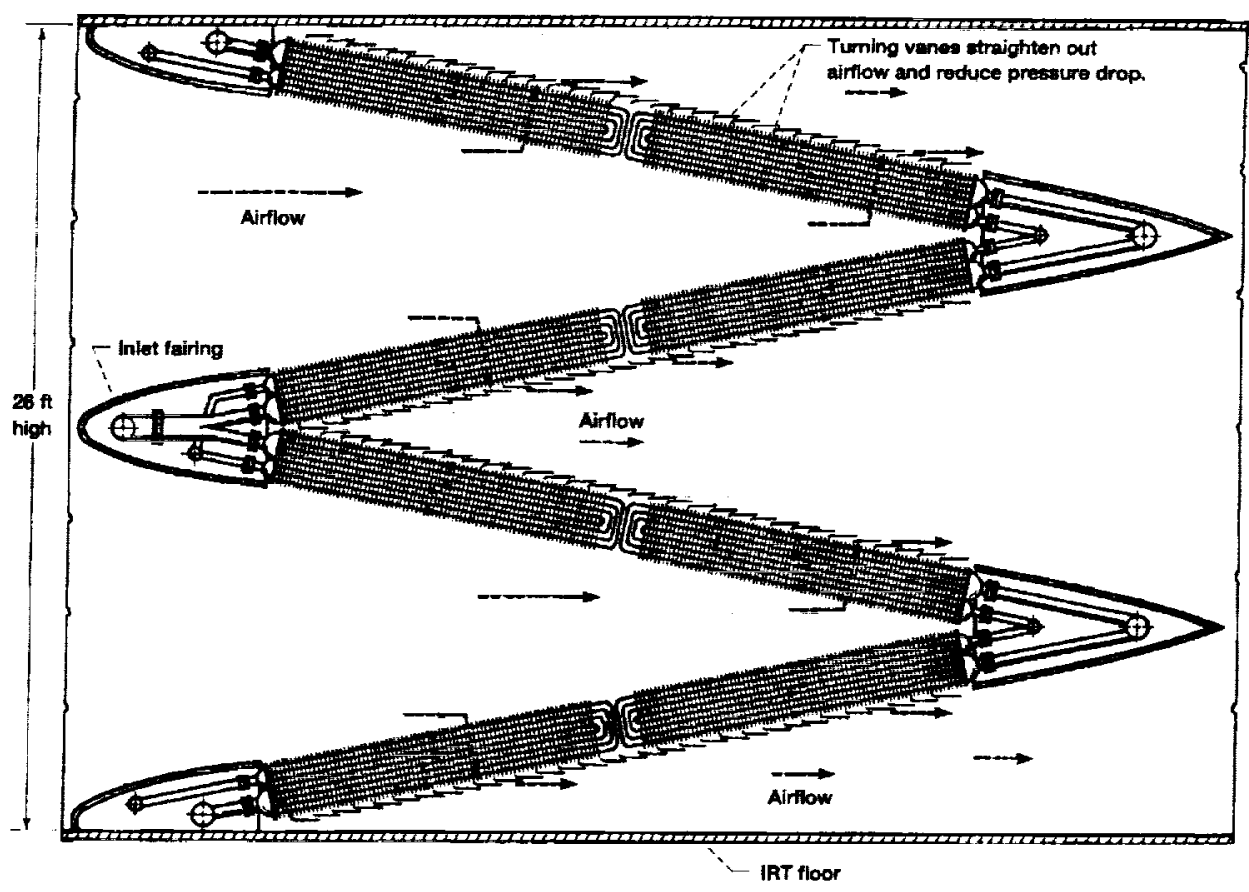

(b) Sectional view of the original heat exchanger.

The flow through the $\mathrm{W}$-shaped heat exchanger is shown schematically.

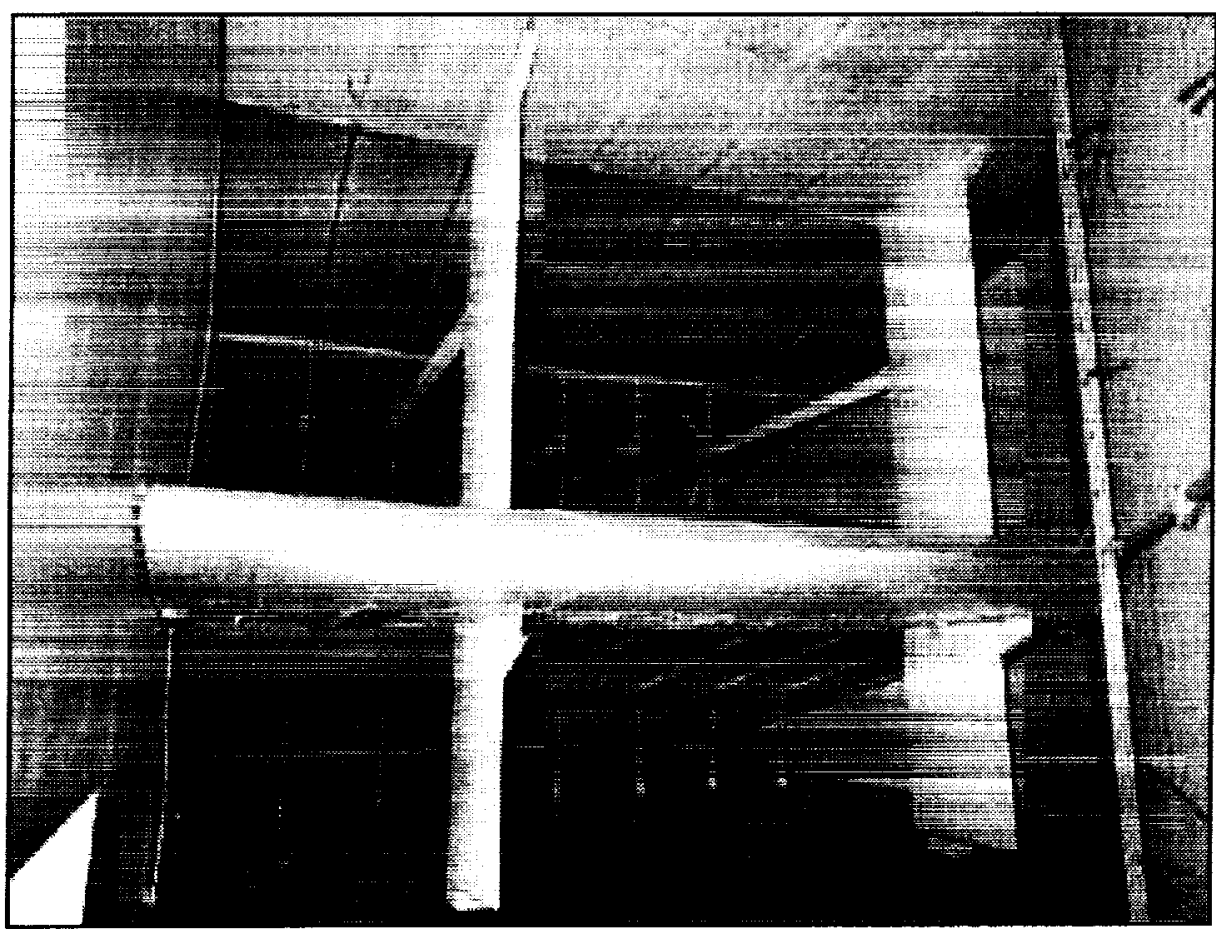

(c) View upstream of the original IRT heat exchanger.

The upper layer of fin-tube panels is out of view. (C-99-1334)

Figure 2. Loop configuration of the IRT before the 1999 modifications. 


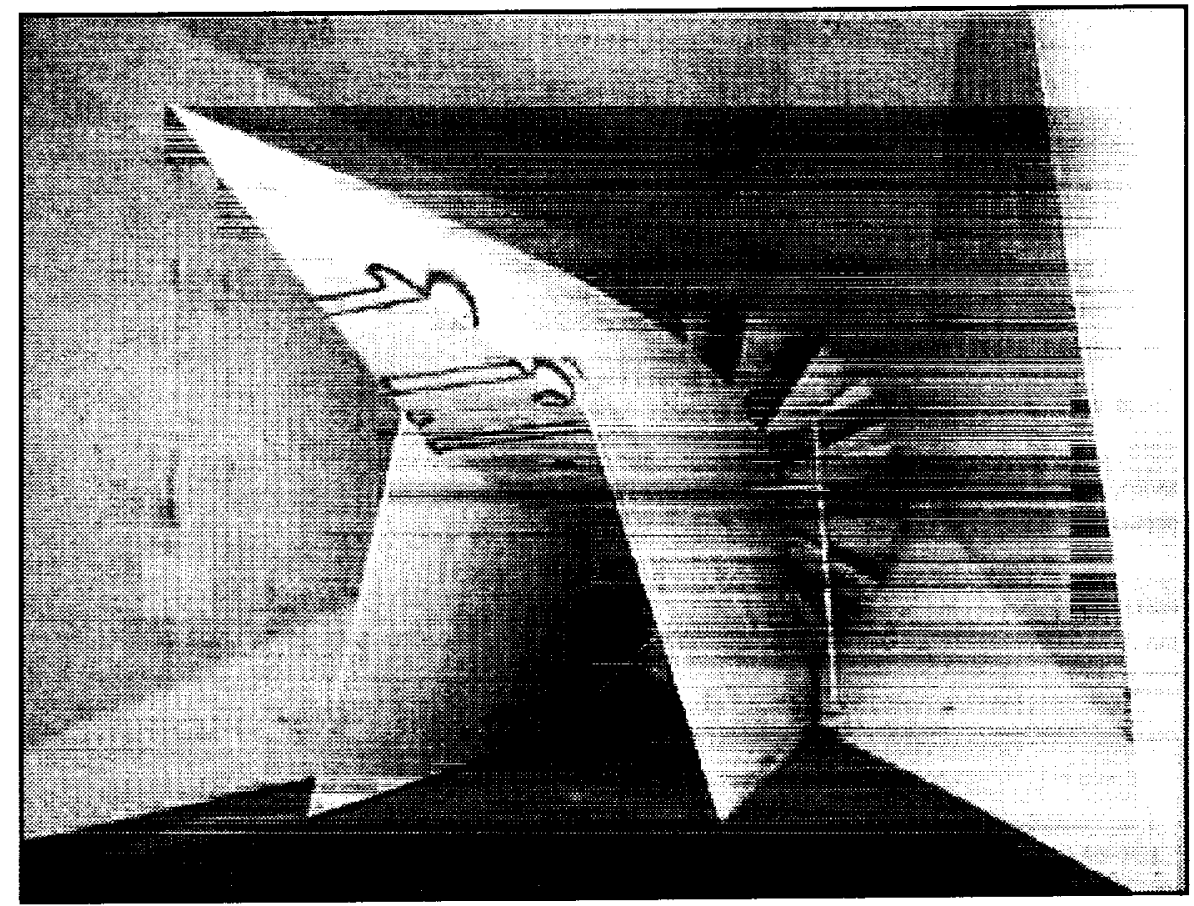

Figure 3. View upstream of the IRT fan and motor housing. The two long fairings over the legs of the motor support platform cause large variations in downstream air velocities.

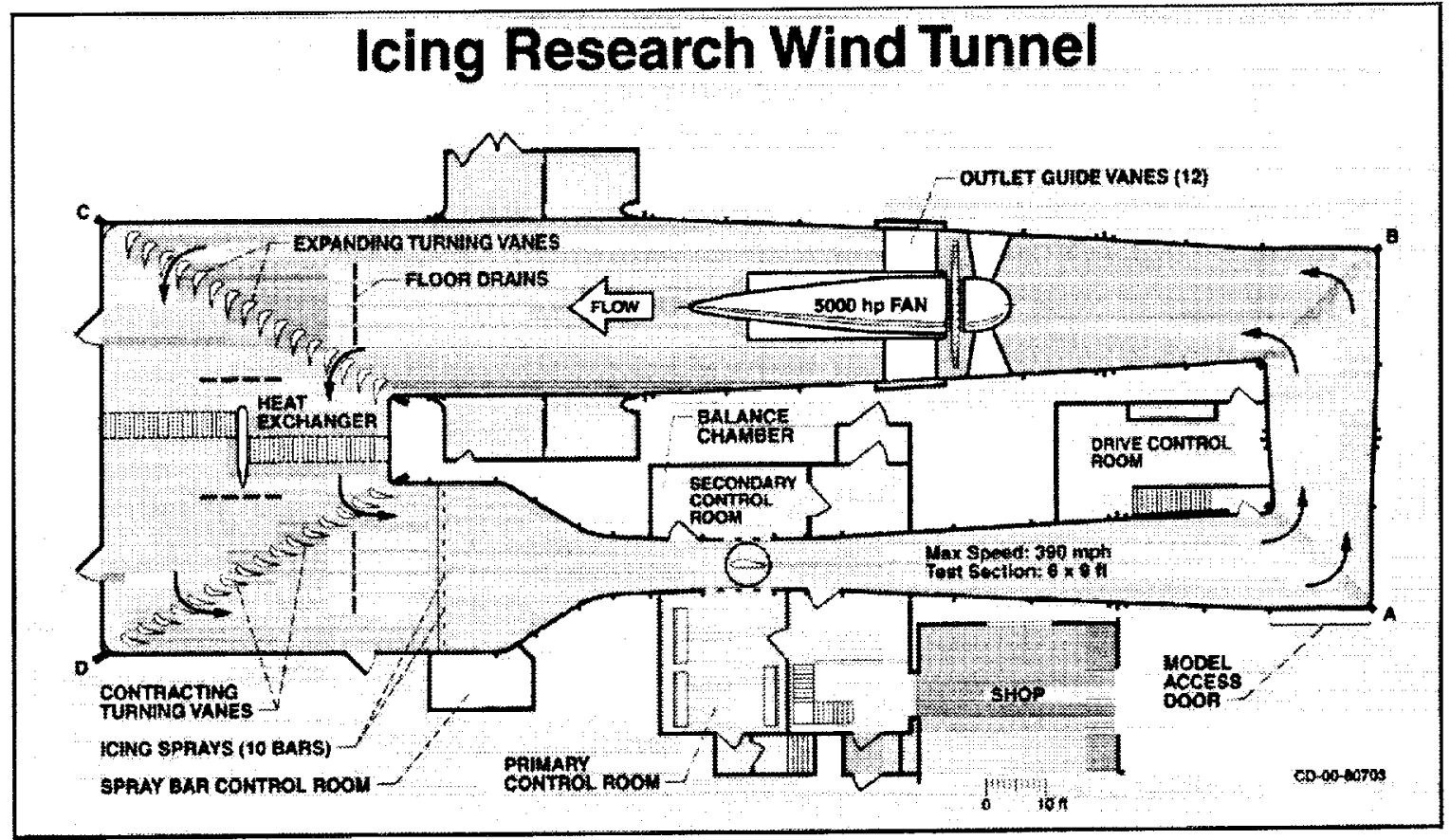

Figure 4. Loop configuration of the IRT after the 1999 modifications. The width of the new C-D leg has been increased 69 percent to accommodate a flat heat exchanger, new turning vanes have been installed in Corners $C$ and $\mathrm{D}$, and new outlet guide vanes have been installed around the fan motor housing. The electronic controls in the drive control room have also been replaced. 


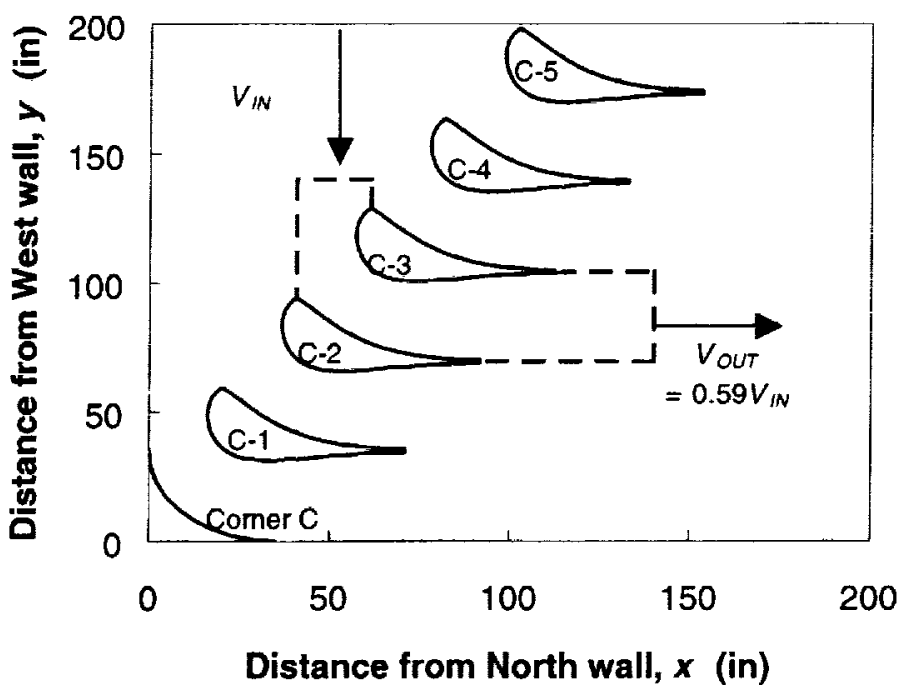

(a) Corner $\mathrm{C}$ cascade (16 vanes; expansion ratio $=1.69: 1$ )

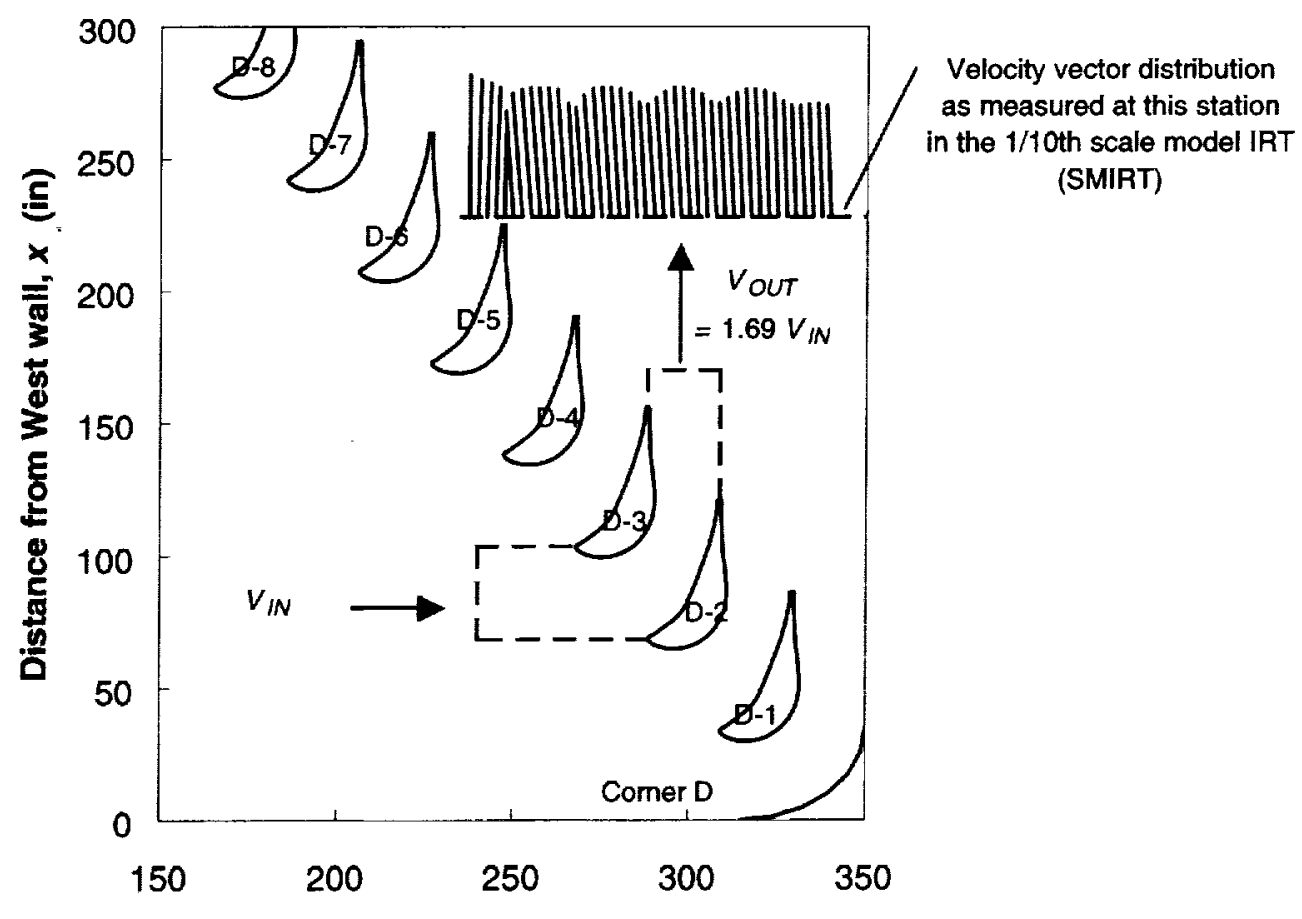

Distance from North wall of Stilling Chamber, $y$ (in)

(b) Corner D cascade (16 vanes; contraction ratio $=0.59: 1$ )

Figure 5. Aerodynamic shapes of replacement turning vanes in Corners $C$ and $D$ of the modified IRT. 


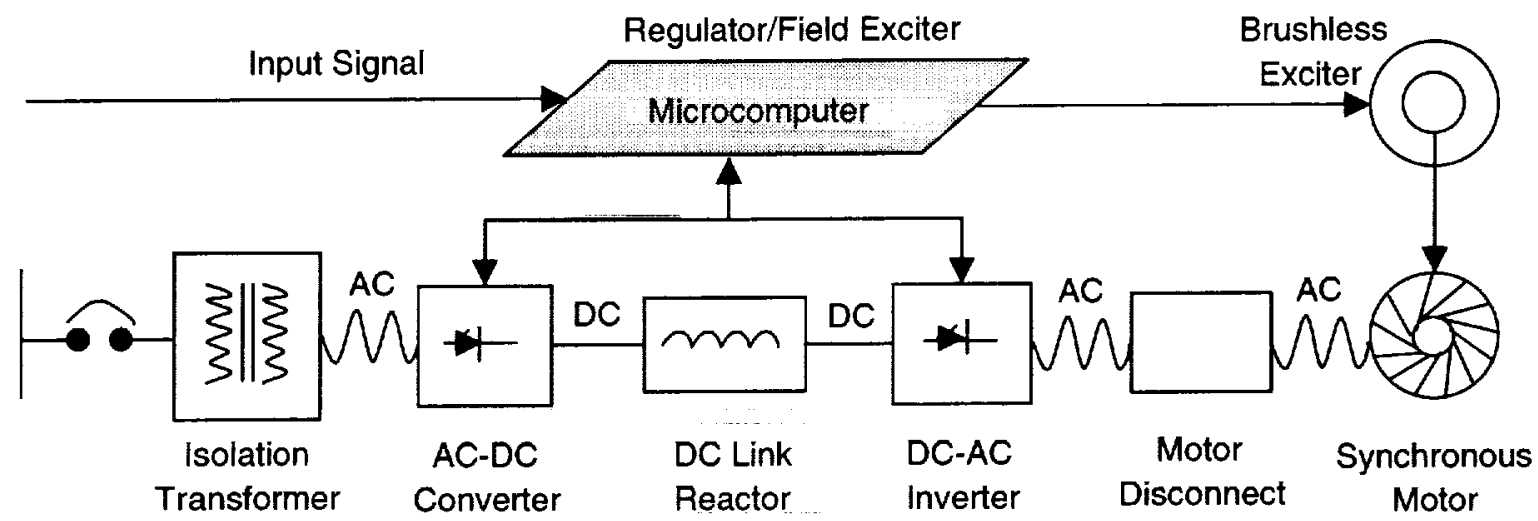

Figure 6. Block diagram representing the various components and functions of the IRT Varichron drive system. Only the obsolete microcomputer was upgraded during this program.

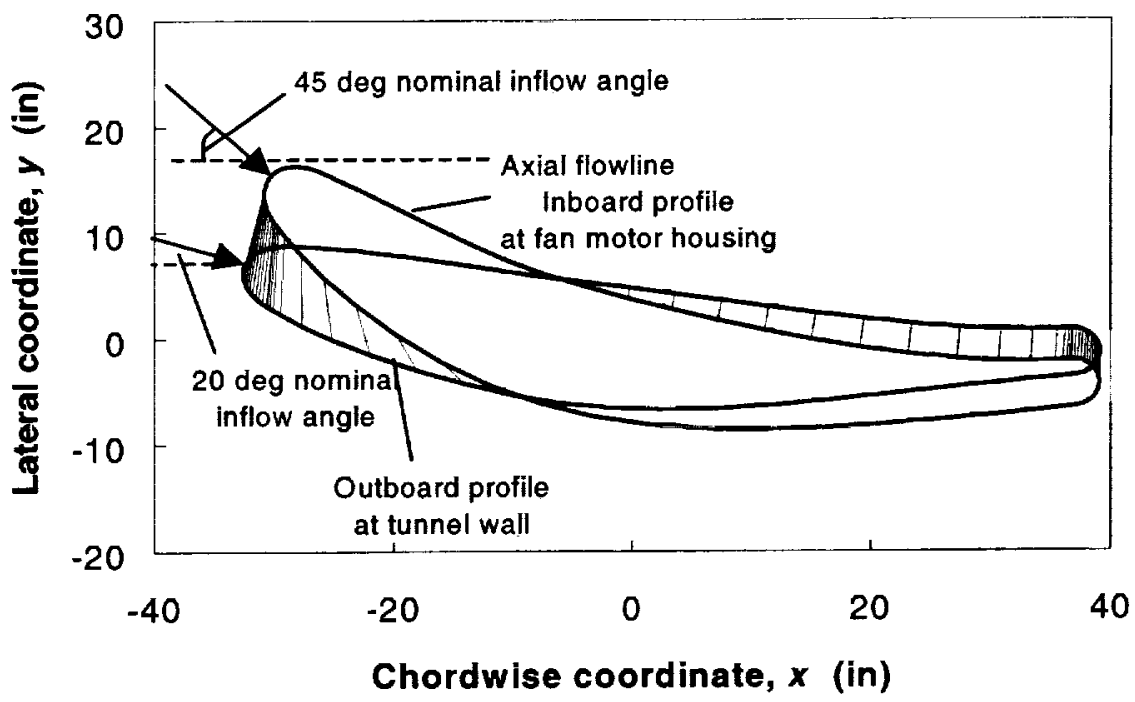

Figure 7. Aerodynamic shape of fan outlet guide vanes installed in the modified IRT. 


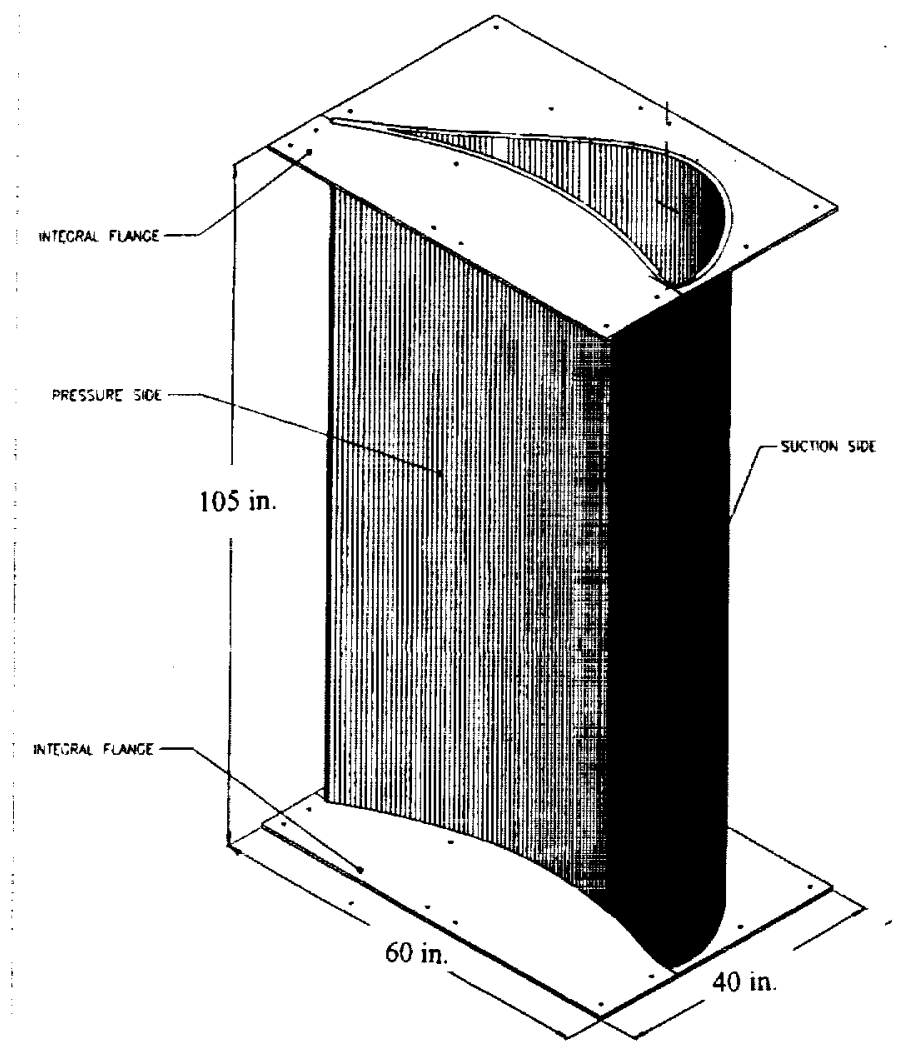

(a) Layout of a typical middle-tier segment, with integral end flanges for bolting to the lower and upper tiers of segments.

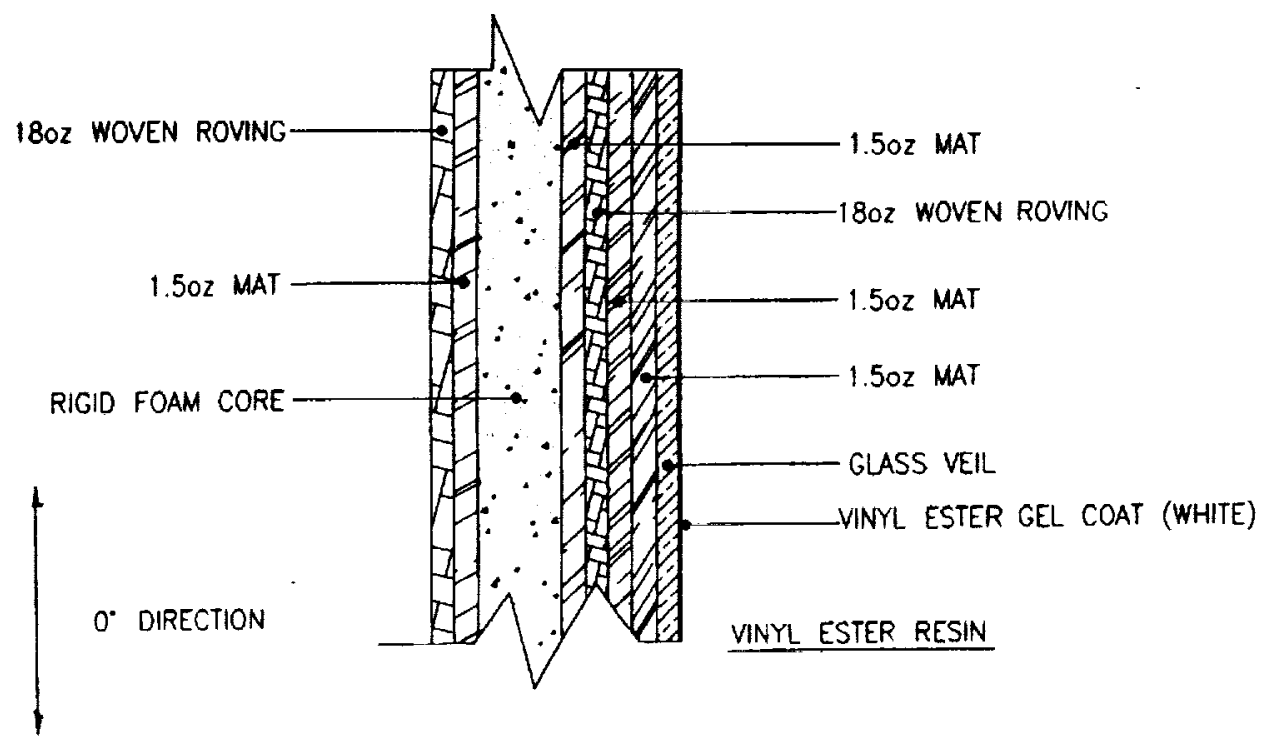

(b) Laminate schedule for walls of the turning vanes, showing glass fiber reinforcement

Figure 8. Structural configuration of the new turning vanes in Corners $C$ and $D$. Each vane is composed of three segments; each segment is fabricated in two molded halves that are bonded together at leading and trailing edges. 


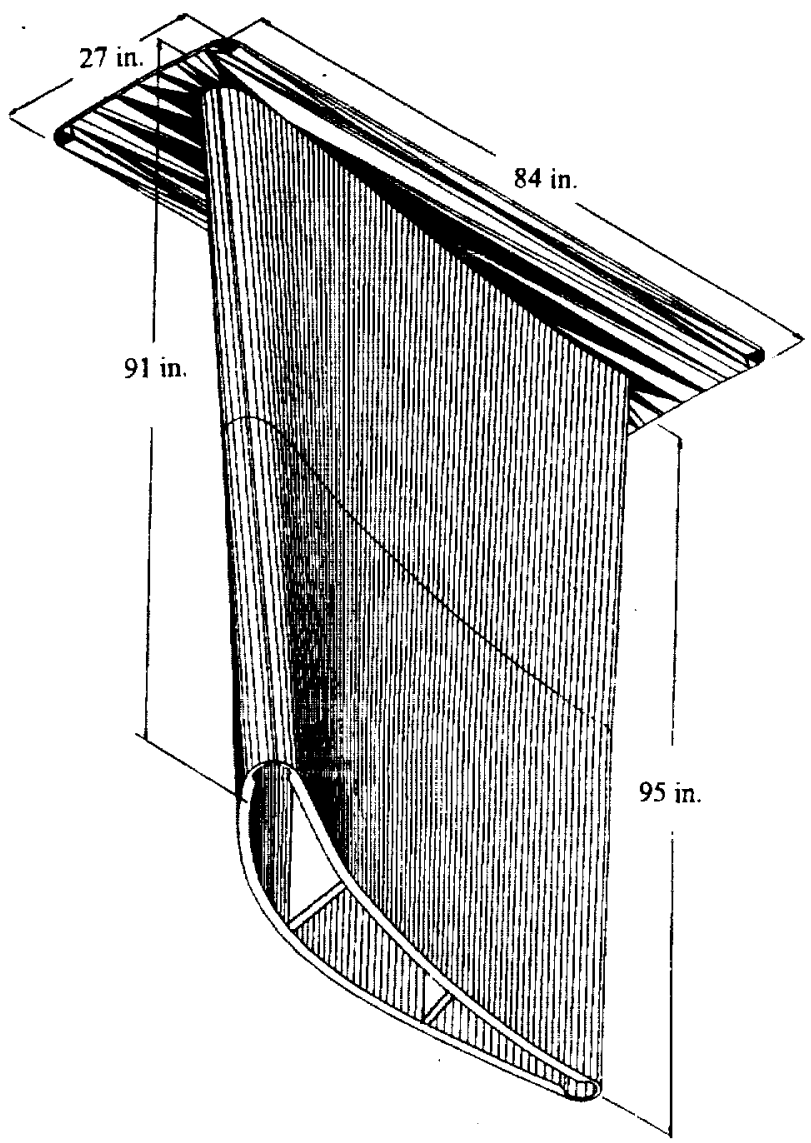

(a) Layout of hollow airfoil with two internal spars. Each airfoil is fabricated in two molded halves that are bonded together at leading and trailing edges. Flange ends are bolted to the tunnel wall. Inner ends slide in sockets bolted to the fan nacelle.

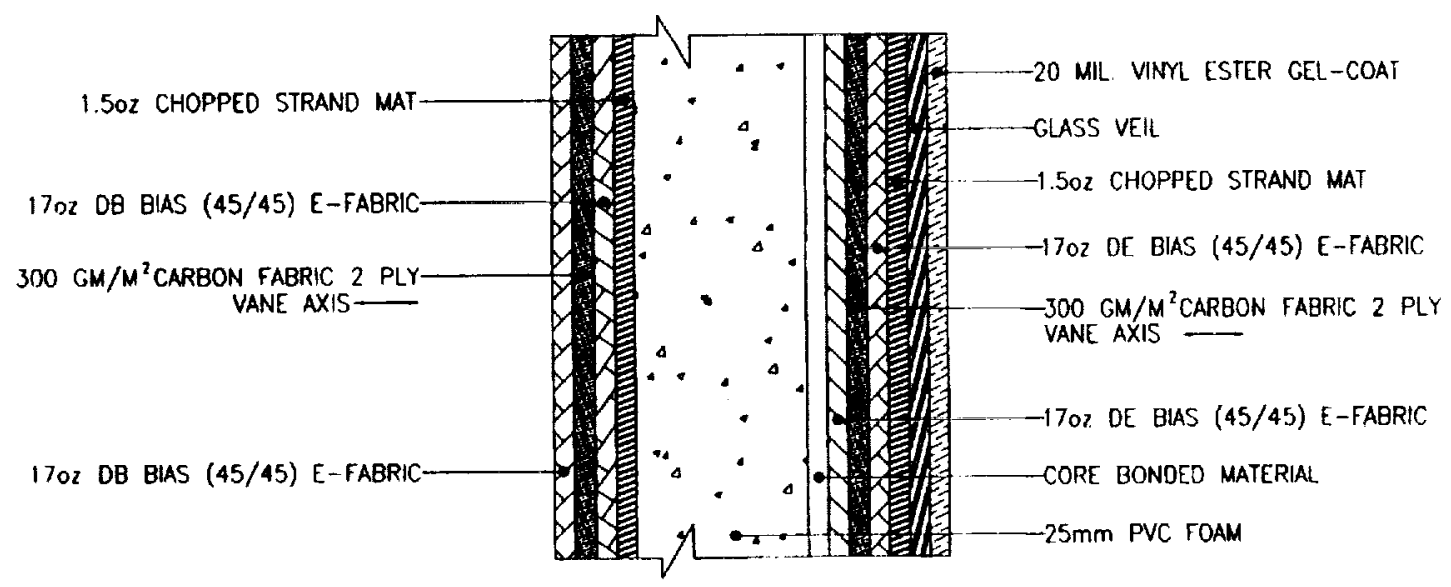

(b) Laminate schedule for OGV's, showing glass and carbon fiber reinforcement.

Figure 9. Structural configuration of the new fan outlet guide vanes (OGV's). 


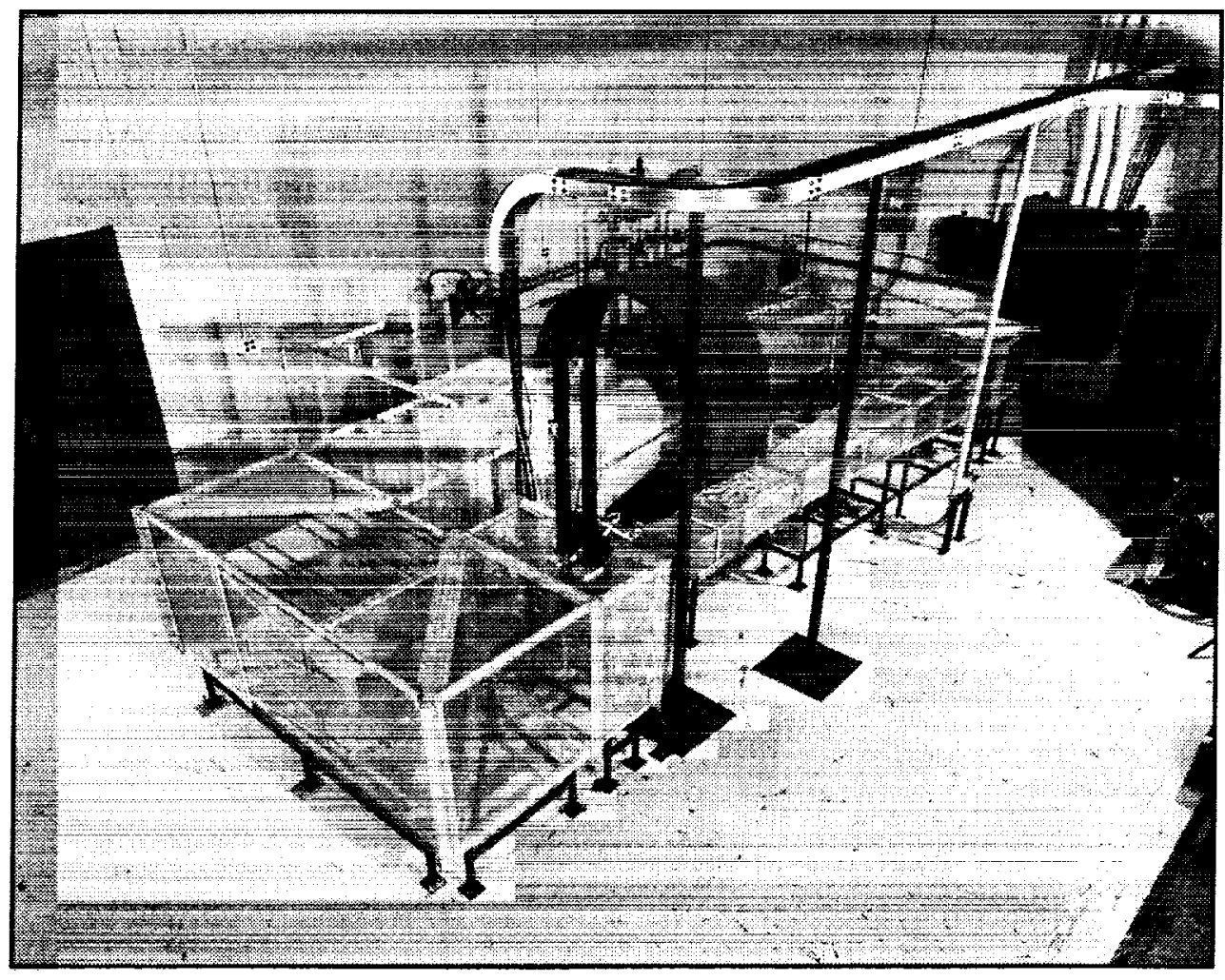

(a) The SMIRT in its initial configuration, modeling the original IRT loop. Corner D is in the foreground. The fan is in the rear, under the safety shield, and is driven by an air turbine. (C-1996-2408)

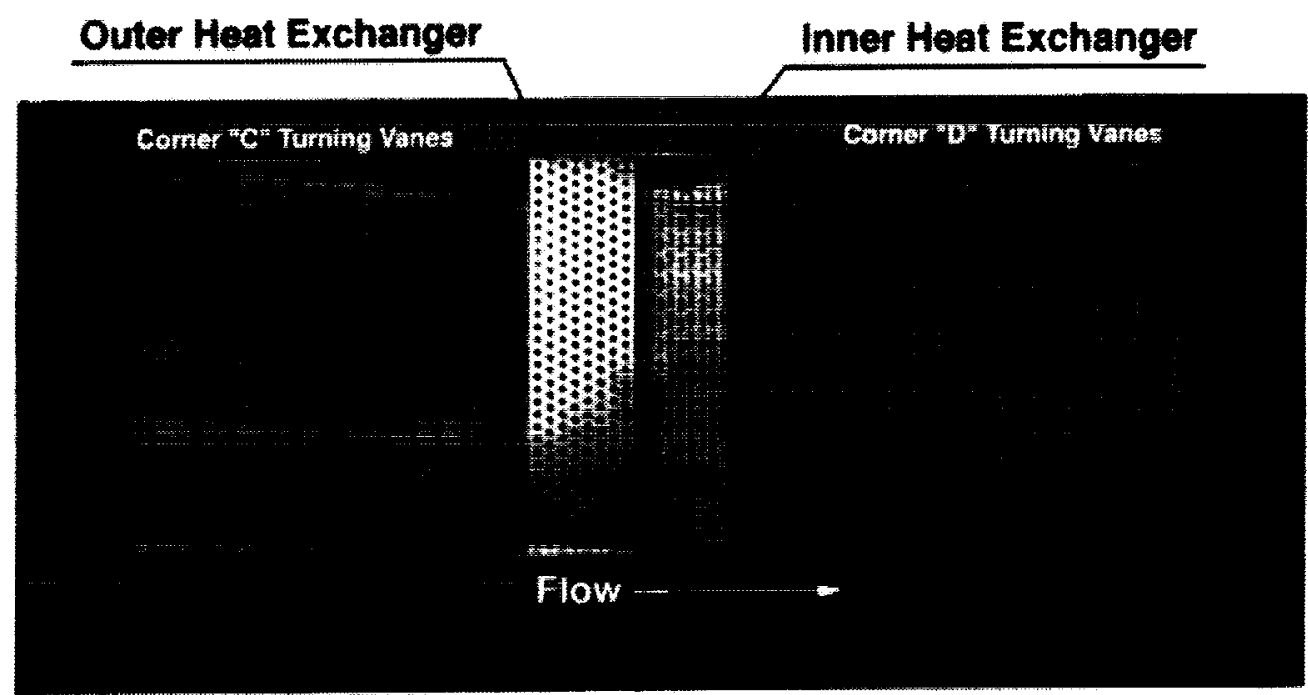

(b) Elevation view of the modified C-D leg. The end wall has been removed to show (1. to r.) the new Corner C turning vanes, the outer and inner replacement heat exchanger units, and the new Corner D turning vanes.

Figure 10. The 1/10th scale model of the IRT (SMIRT) showing the two configurations of the C-D leg tested during the design verification program. 


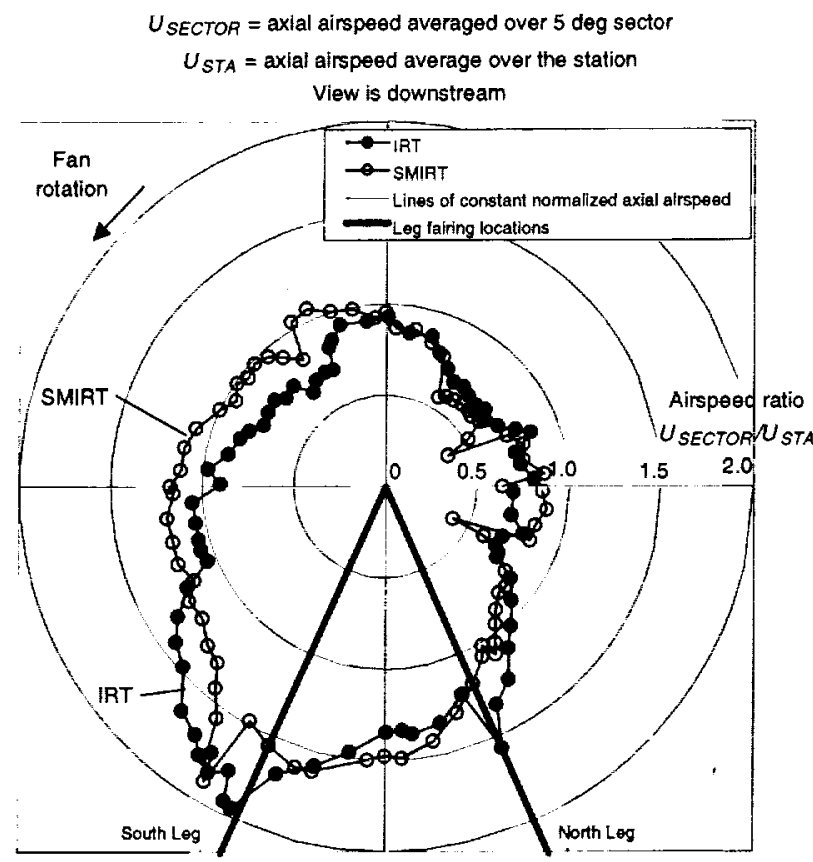

(a) Polar distribution at Vent Tower station, without fan OGV's. The view is downstream. The close agreement shown between the SMIRT and IRT data at this station verifies that the SMIRT accurately models the flow quality in the IRT.

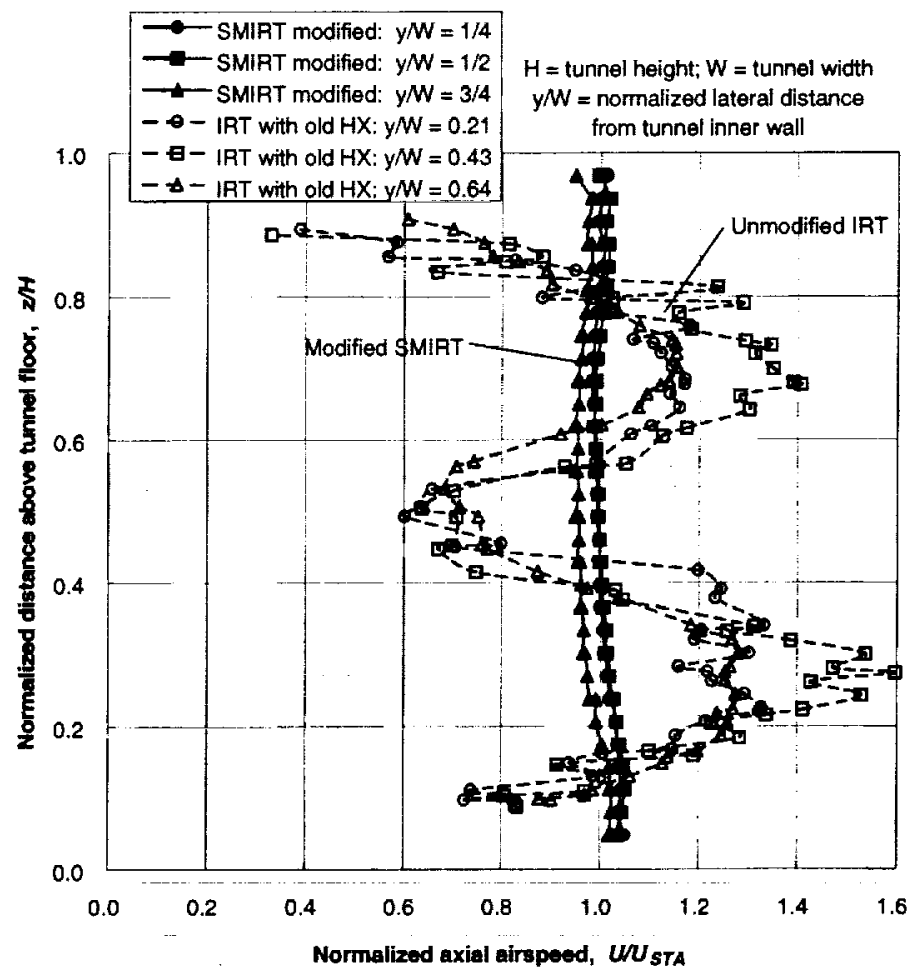

(b) Vertical distribution in the Stilling Chamber. The large distortions in airspeed caused by the old W-shaped HX in the IRT are eliminated in the modified SMIRT with its flat HX.

Figure 11. Comparison of SMIRT and original IRT distributions of axial airspeed across tunnel stations. 


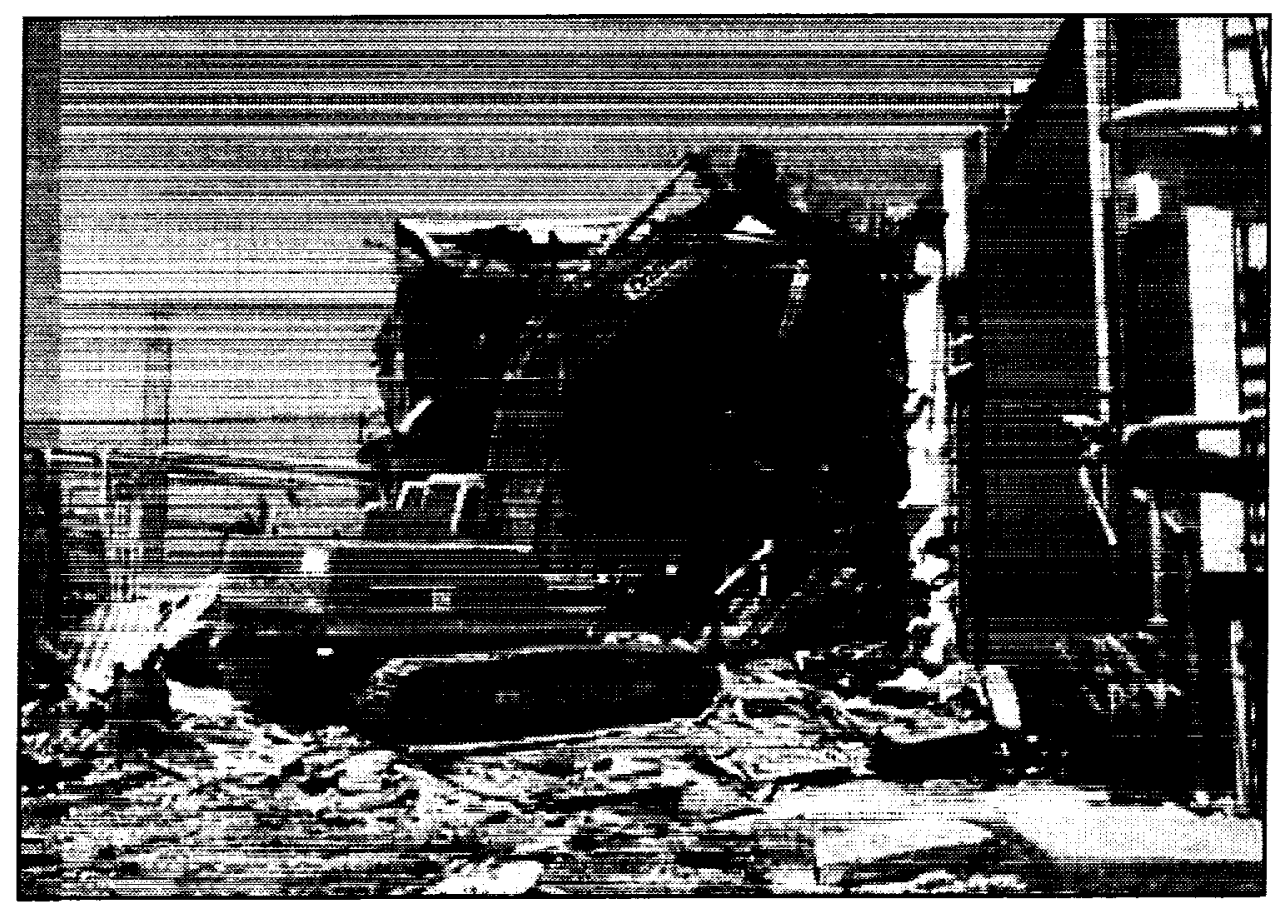

Figure 12. Demolition of Corner $D$ and the original heat exchanger. Corner $C$ is in the background. (C-99-1452)

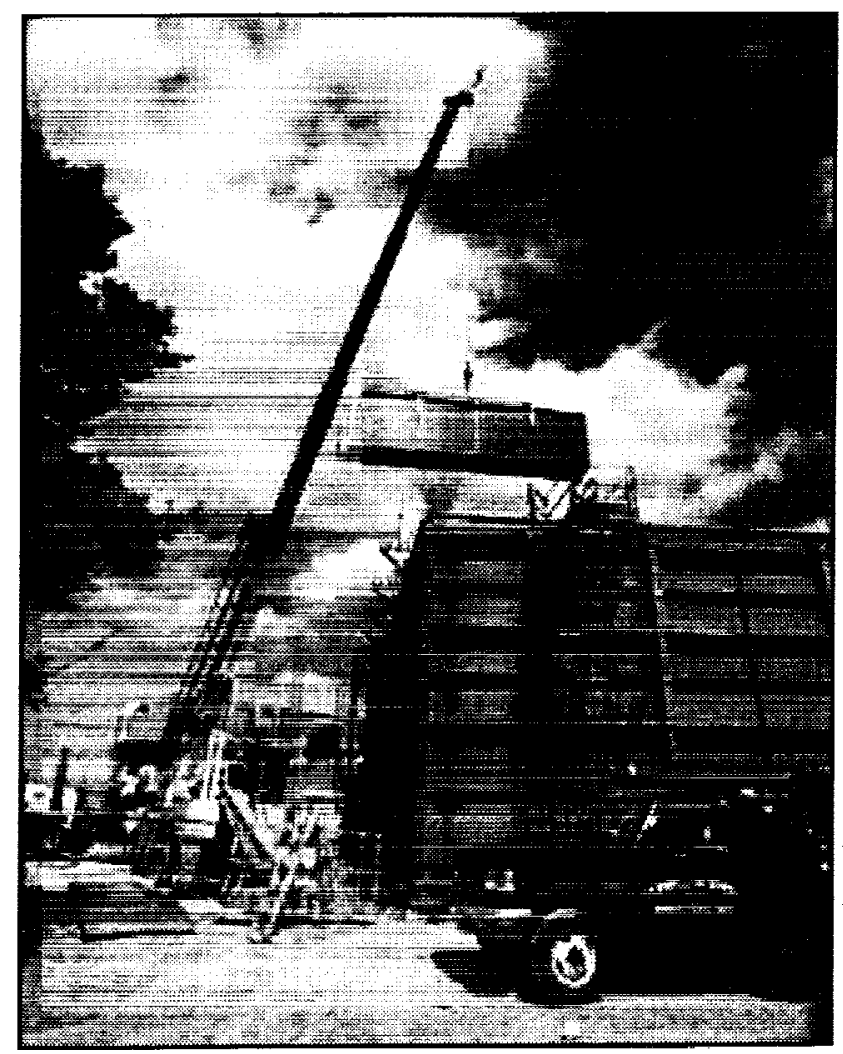

Figure 13. Construction of the new Corner $D$ and placing of one of the eight heat exchanger modules. (C-99-1997) 


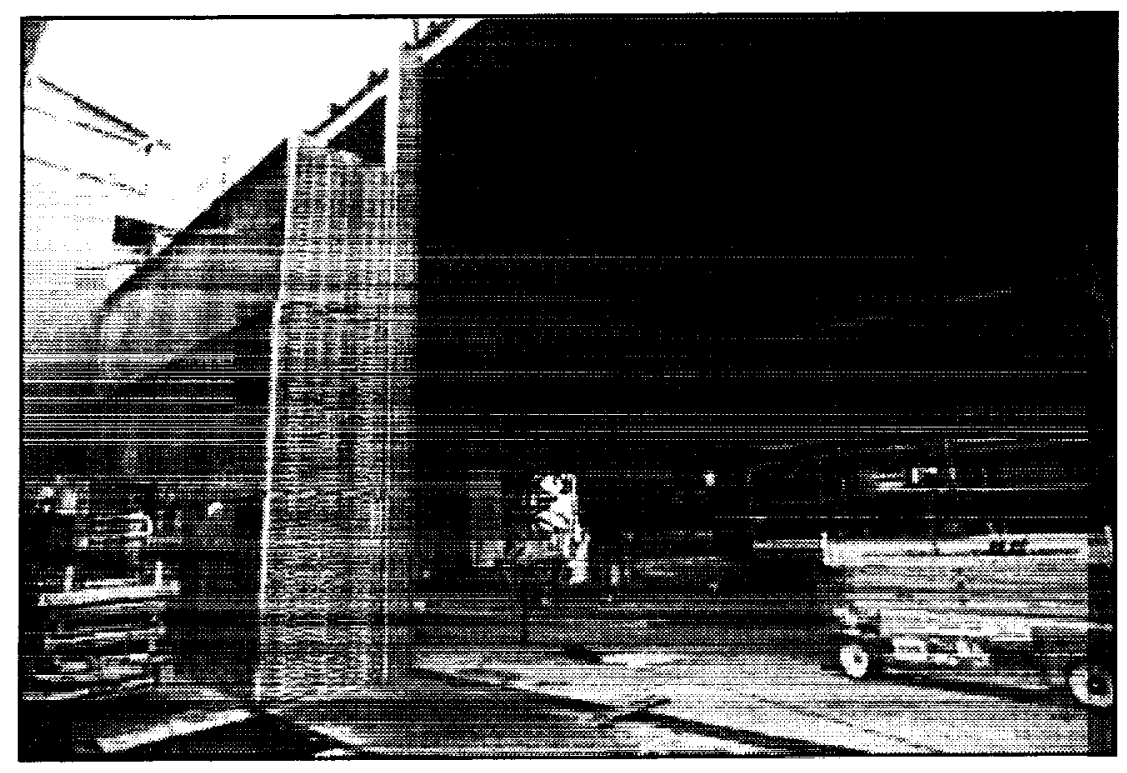

Figure 14. Interior view of the new Corner $\mathrm{C}$ during construction, with three heat exchanger modules in place. The end turns in the aluminum coolant tubes indicate the locations of the three streamwise zones in each module. The coolant flow in each zone can be controlled independently, to minimize temperature variations in the outflow. (C-99-2005)

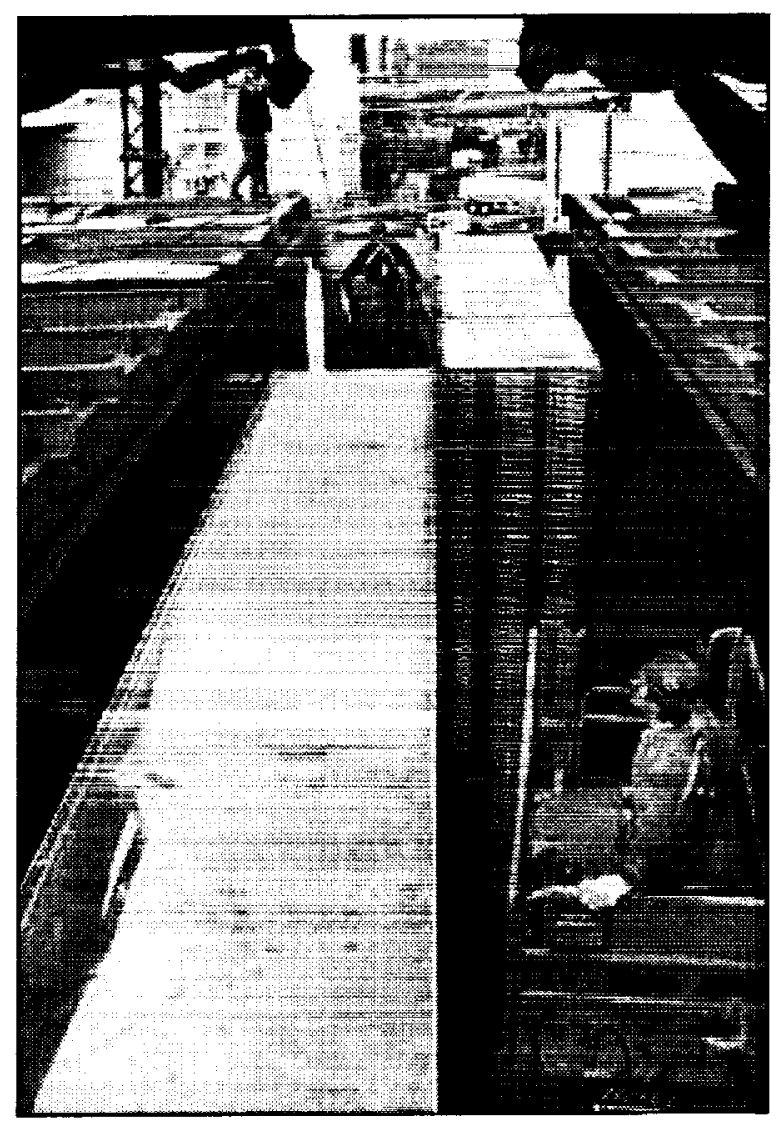

Figure 15. View through the roof of the new C-D leg, showing the offset positions of the two heat exchanger units. The end turns in the coolant tubes are readily accessible for inspection and repair, without loss of active flow area for a corridor between units. (C-99-2178) 


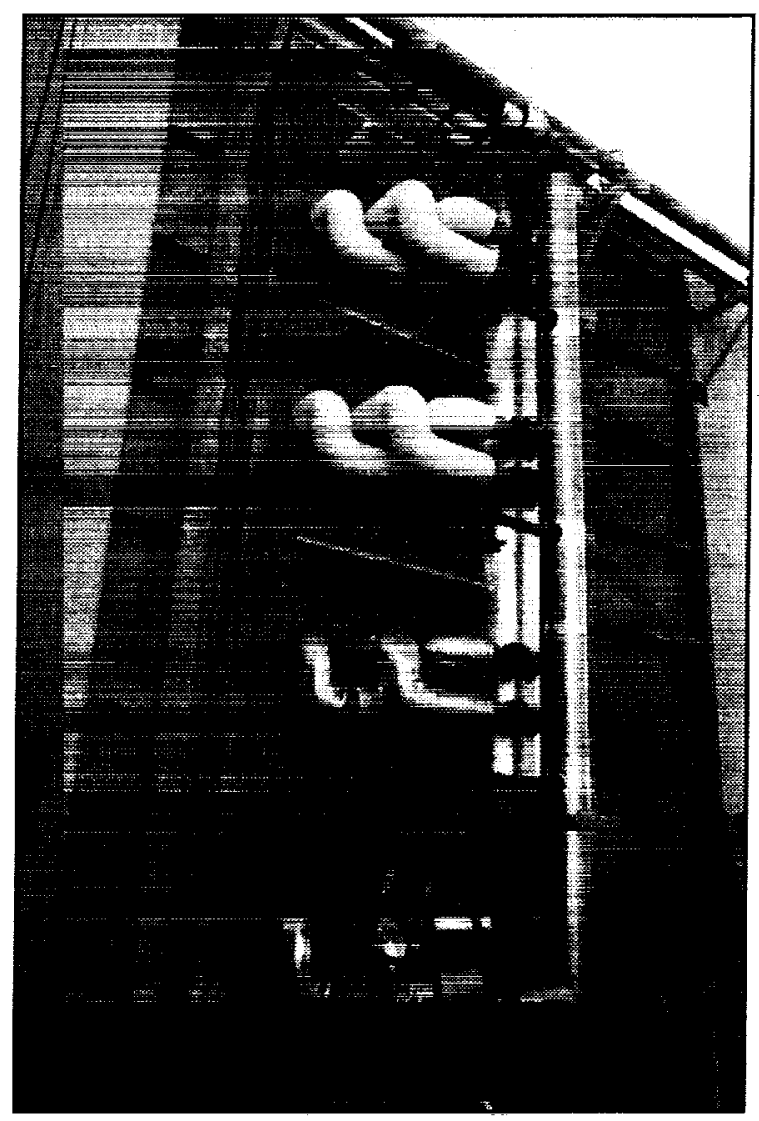

Figure 16. View of the HX coolant supply (smaller diameter) and return (larger diameter) pipes on the West wall of the new C-D leg. Separate pairs of pipes are connected to each of the three streamwise zones in each of the four HX modules that are stacked vertically to form the West HX unit. (C-99-2655)

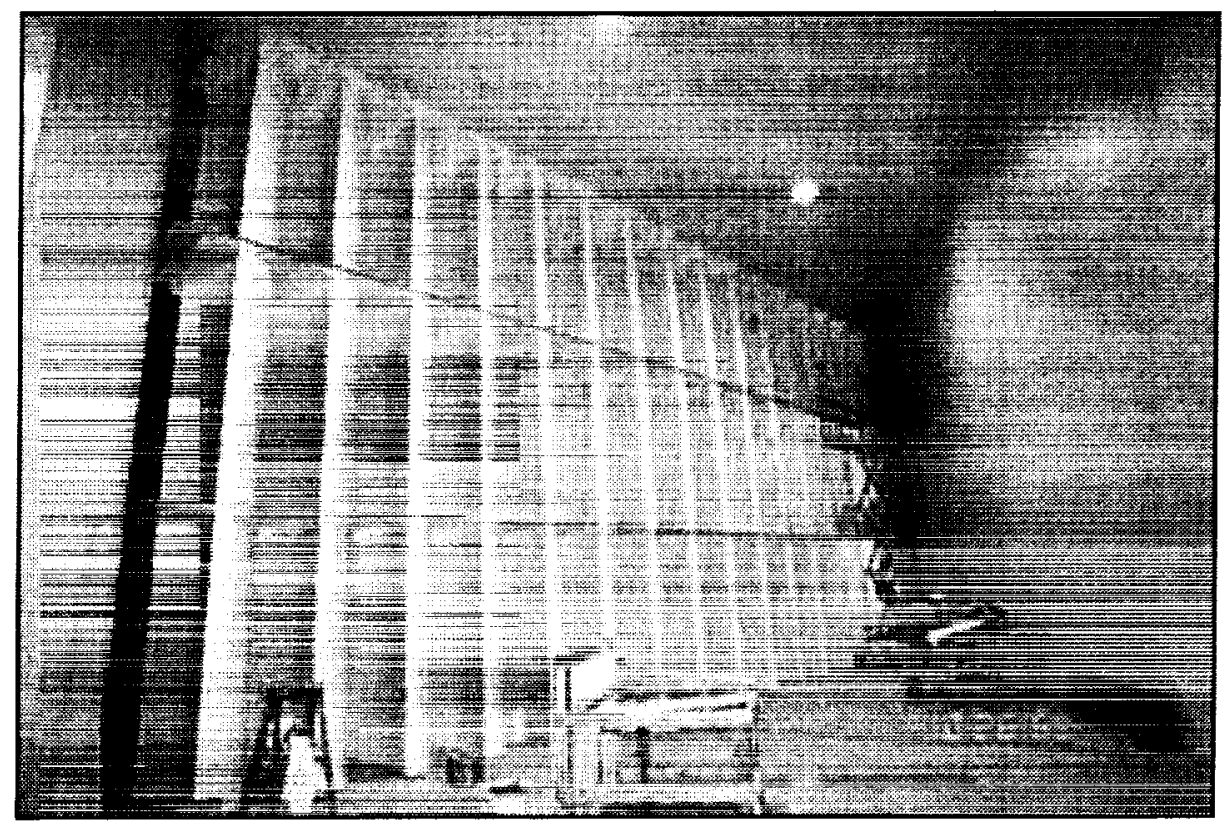

Figure 17. Installation of the new fiberglass-composite turning vanes in Corner $\mathrm{C}$. The horizontal tie plates between the vane segments help carry airloads directed outward along the comer diagonal. Socket connections at the ceiling provide for differential thermal expansion and contraction. (C-99-2287) 


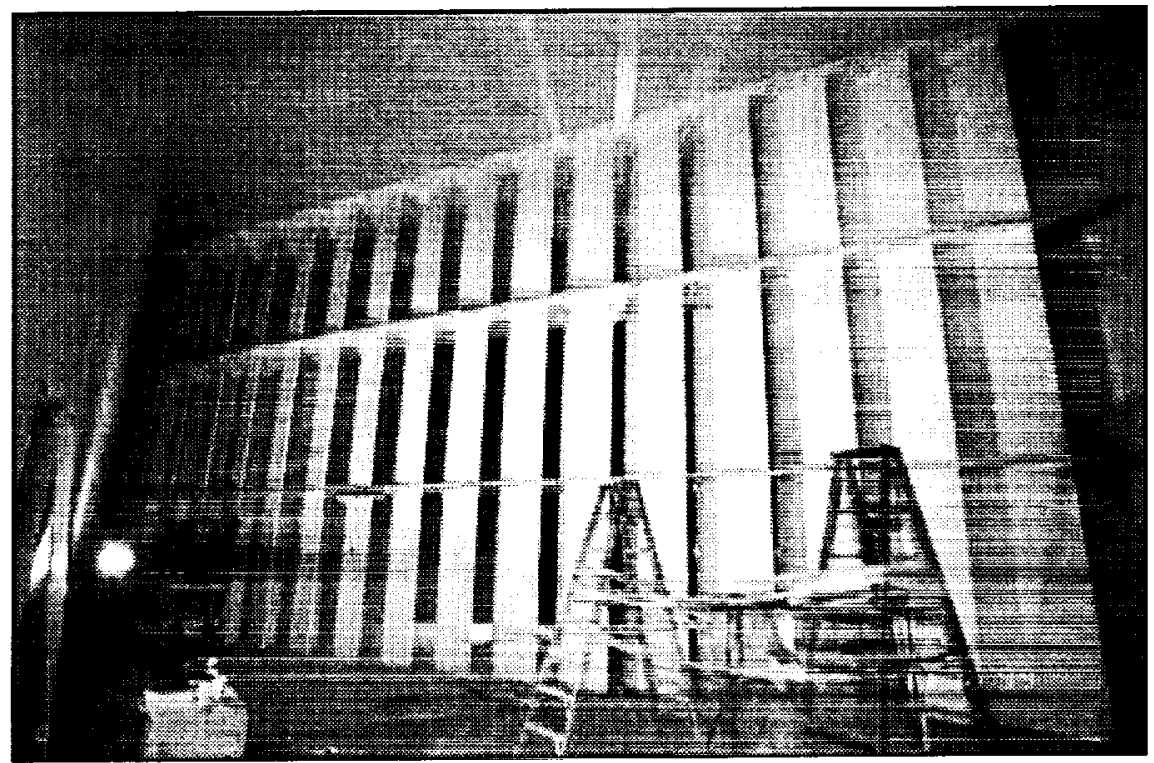

Figure 18. View from the Stilling Chamber, looking upstream at the Corner $D$ turning vanes. The lower segment of the seventh vane from the corner is removable, to provide access to the heat exchanger for a maintenance lift vehicle. (C-99-2285)

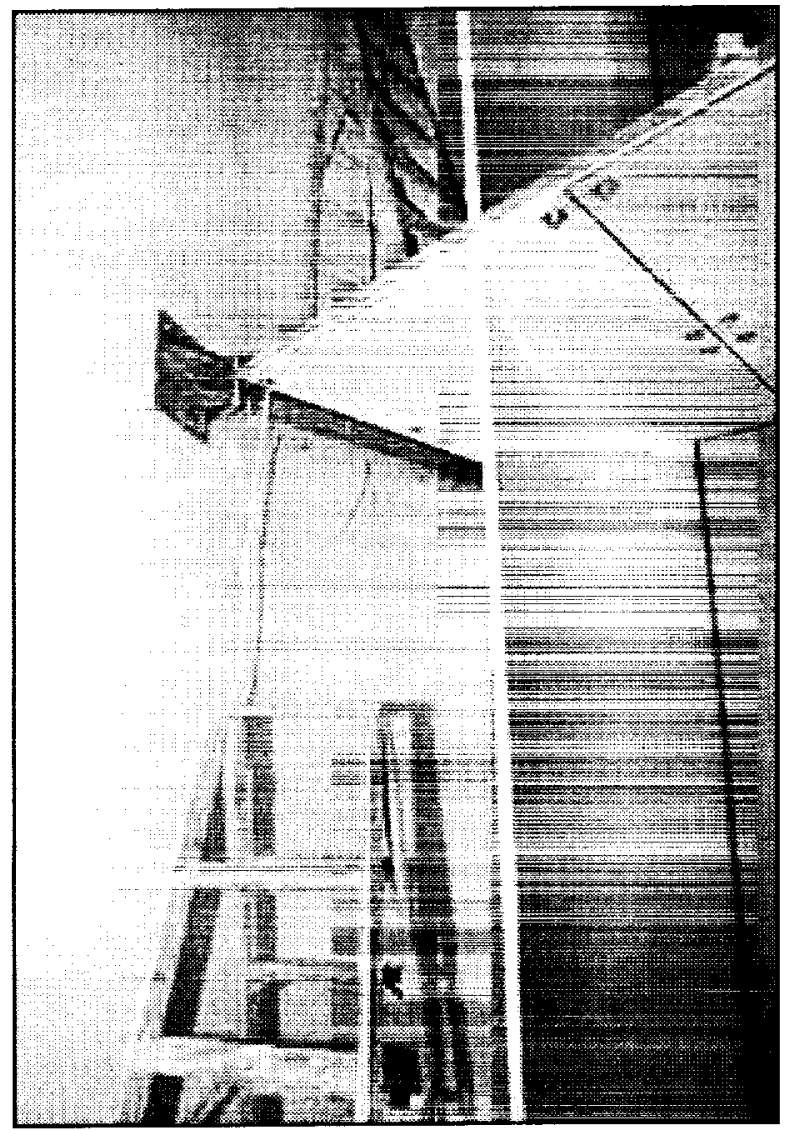

Figure 19. View in Corner $C$ of the trailing edge of vane $C$-1, showing the outer end of a tie plate sandwiched between bolted flanges. The reinforced end of the tie plate bears against brackets on the outer wall of the tunnel. (C-99-2432) 


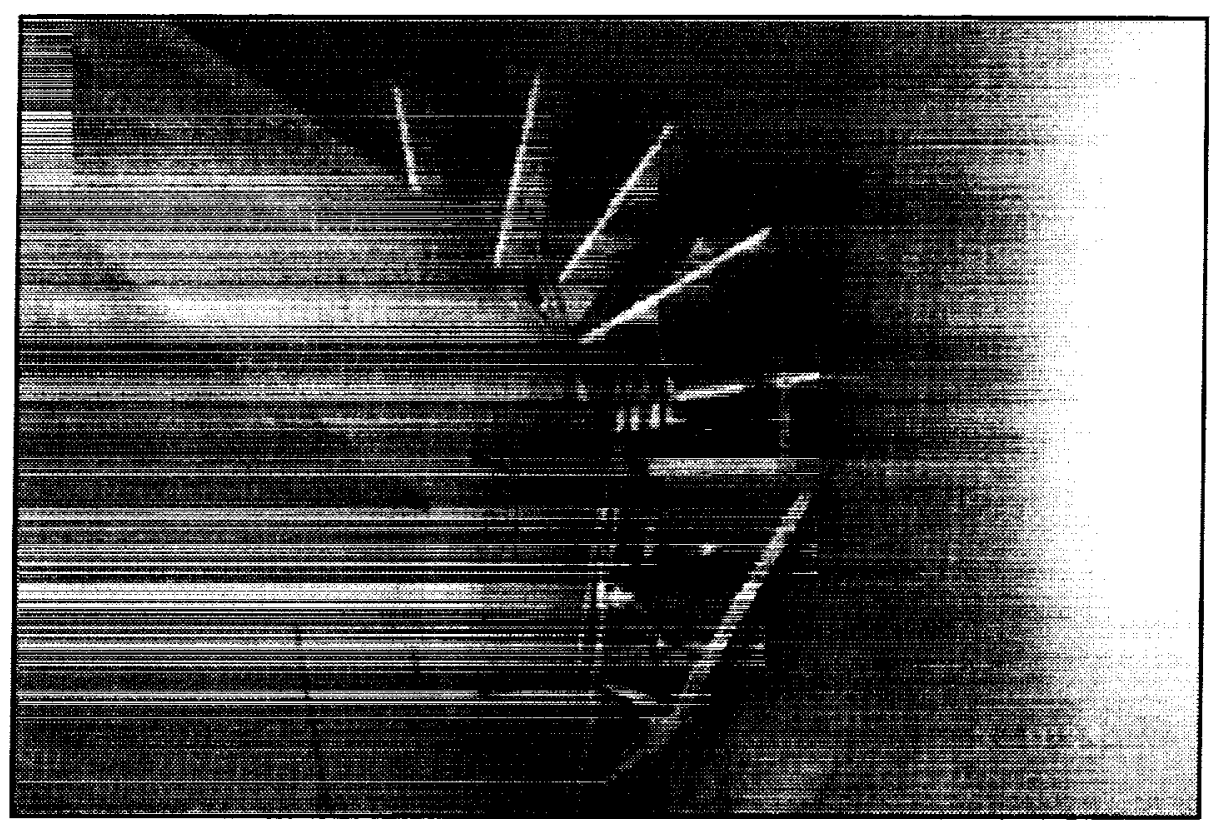

(a) Workers installing a device for accurately measuring the variable wall-to-housing distances around each airfoil. The inner end of each OGV is contour-trimmed to length and fitted with a reinforcing rib before the OGV is hoisted into place. (C-99-2021)

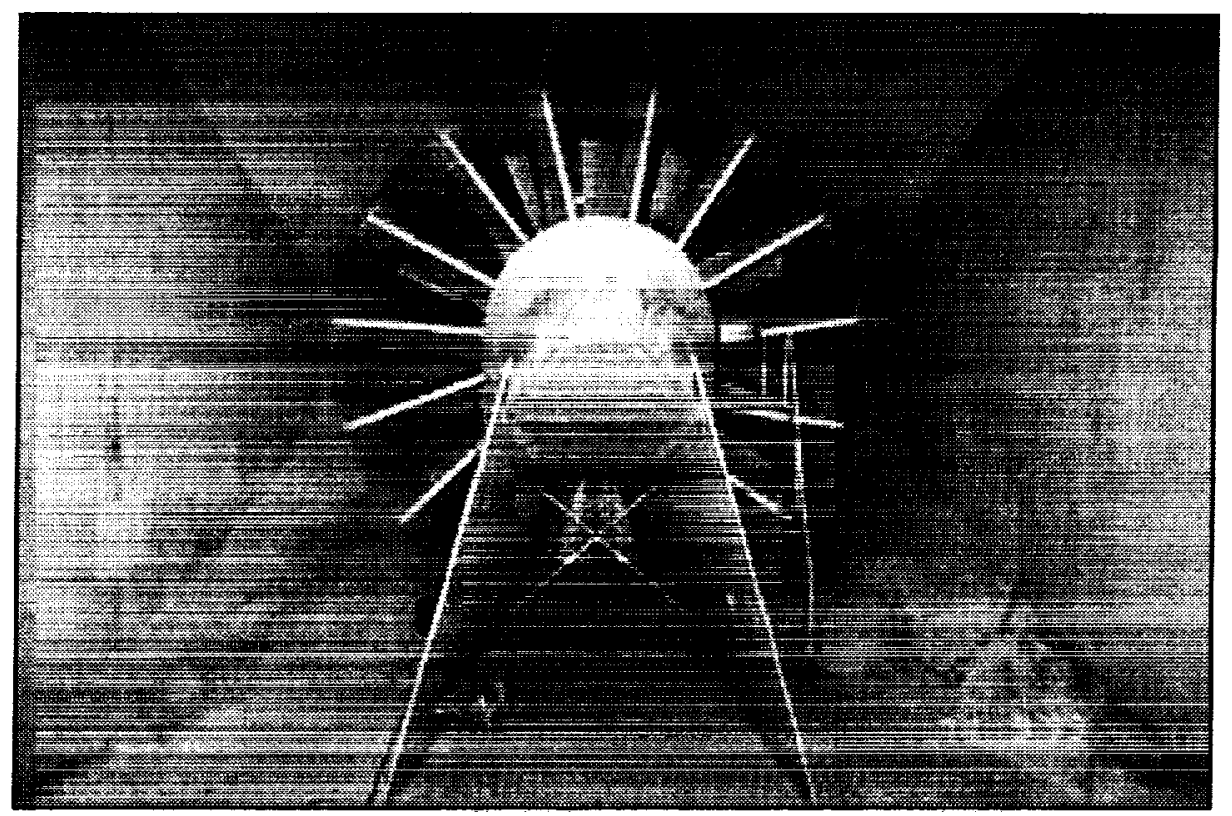

(b) General view of all twelve OGV's in place. The leg fairings take the place of two additional OGV's. The OGV at the six o'clock position has been eliminated because it would block the primary access path to the fan blades. (C-99-2410)

Figure 20. Installation of the fan OGV's around the motor housing. Views are upstream. Fan blades can be seen in the background. 


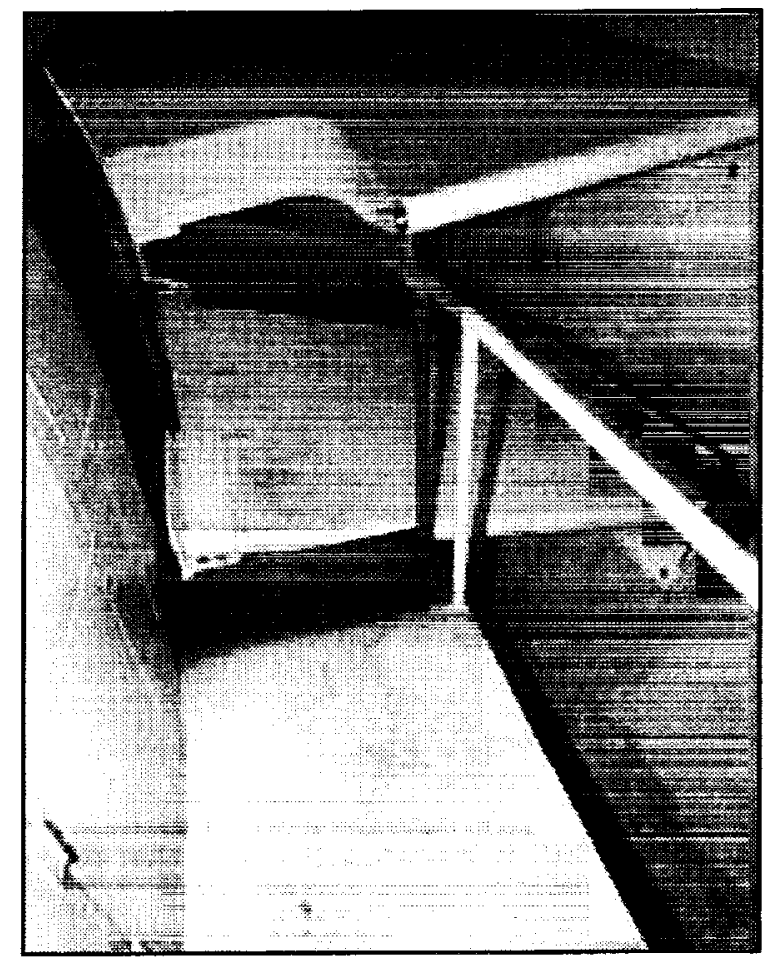

Figure 21. Close-up view of the socket connections between the OGV's and the fan motor housing, to relieve radial thermal stresses. The cutout seen in the trailing edge of one OGV permits an access hatch in the side of the housing to open. (C-99-2408)

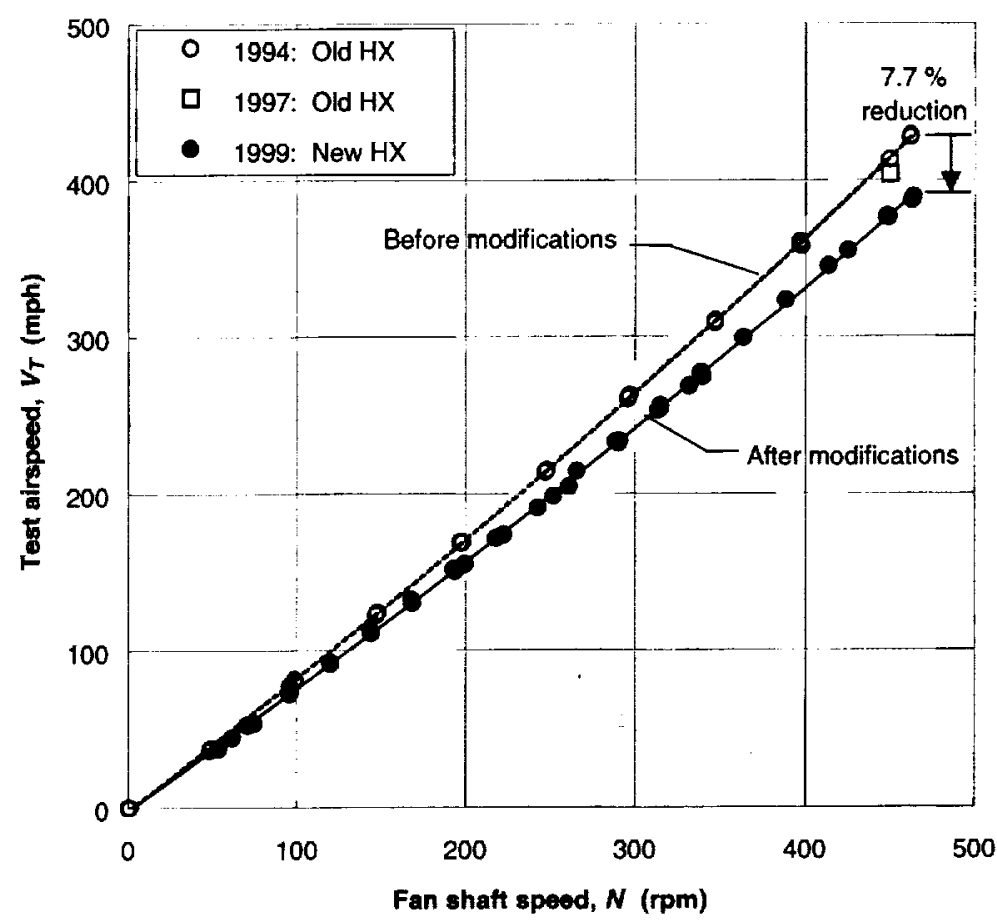

Figure 22. Comparison of test airspeeds achievable in the IRT before and after tunnel modifications. Maximum airspeed was reduced approximately 8 percent. 


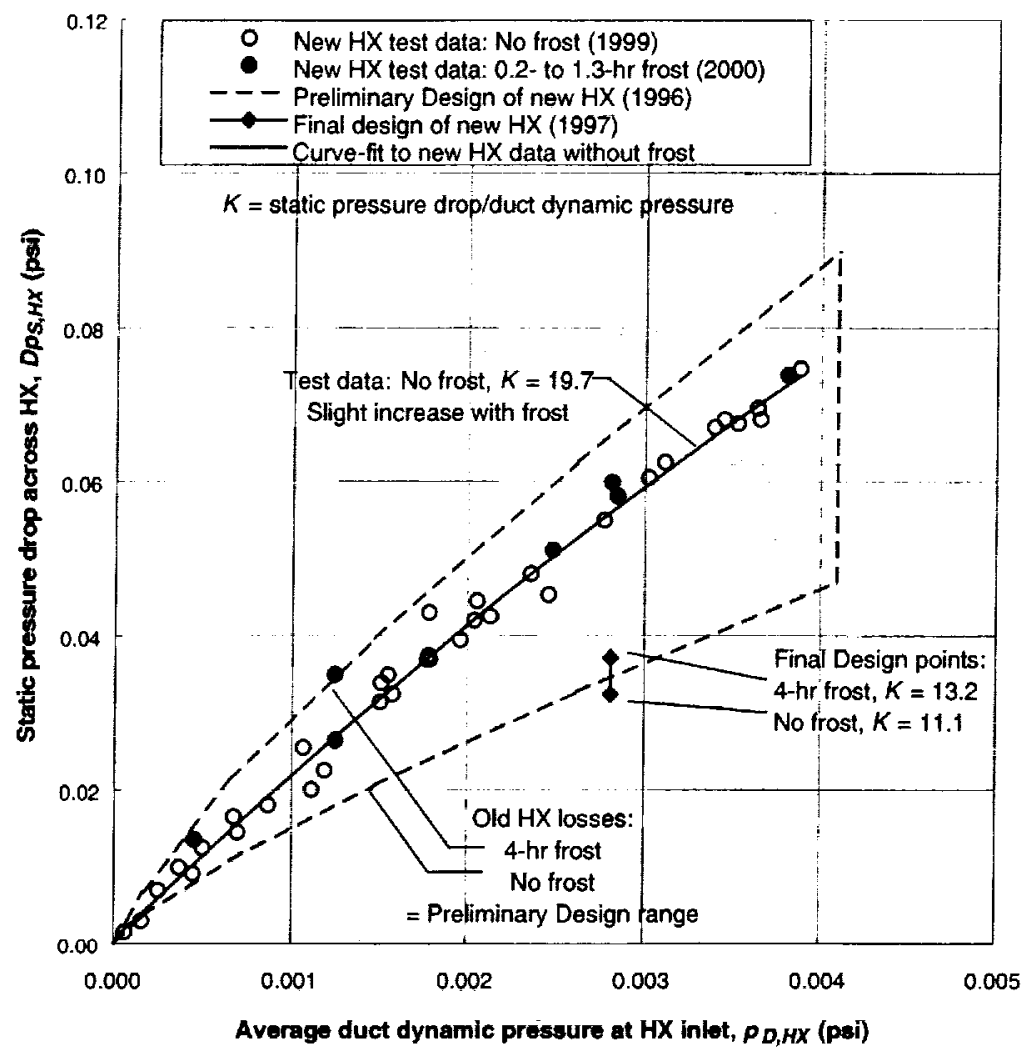

Figure 23. Comparison of measured and design pressure drops across the replacement heat exchanger. Measured pressure drop is approximately 70 percent higher than the final design.

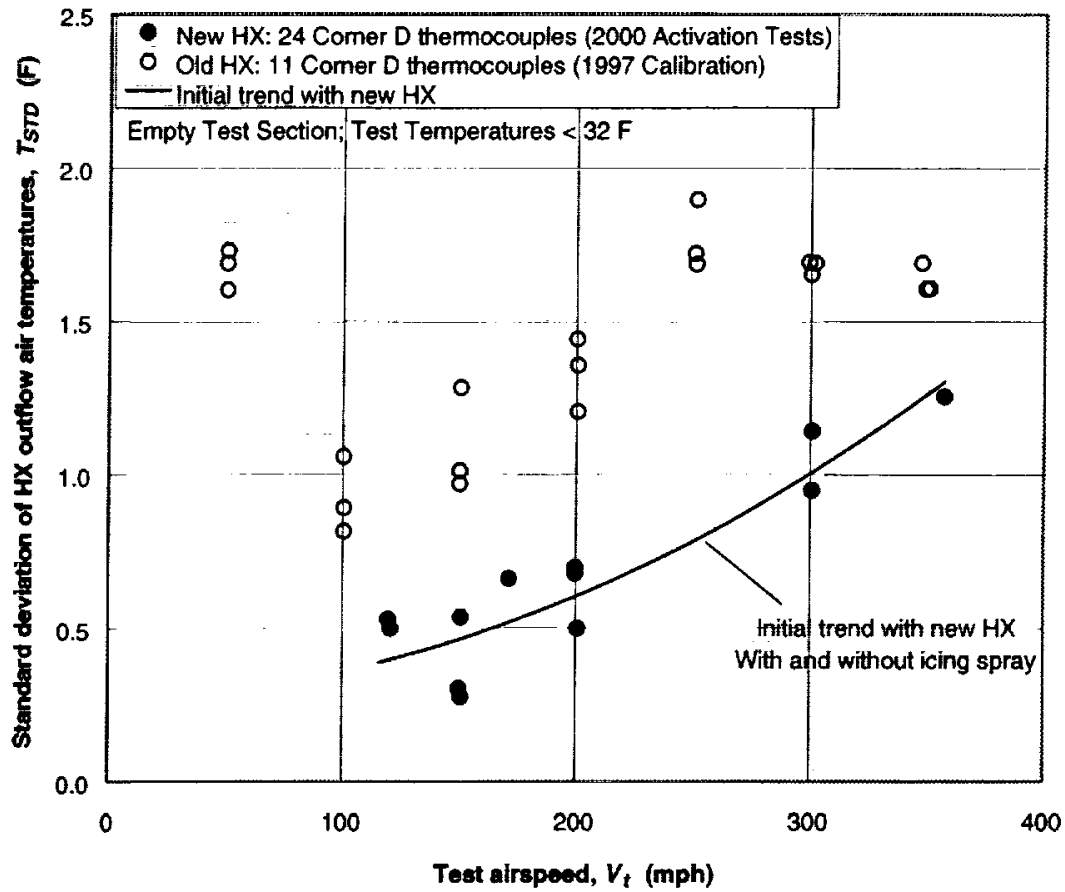

Figure 24. Improvement in the uniformity of temperature in the outflow of the replacement heat exchanger, compared with the original heat exchanger. The standard deviation of the temperatures measured with the array of thermocouples in Corner D is used as the measure of uniformity. 


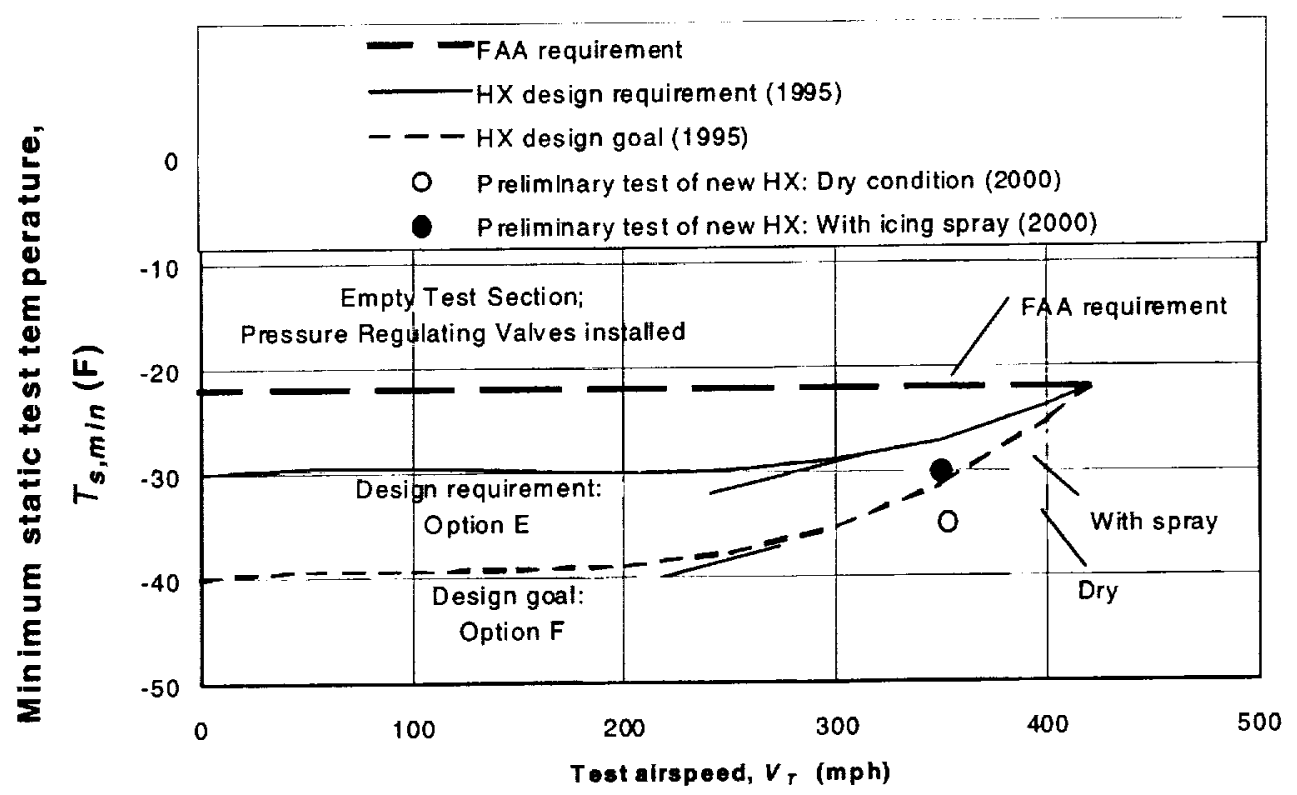

Figure 25. Preliminary lowest-temperature data obtained with the pressure regulating valves in place and fully open.

\footnotetext{
$T_{C}, T_{D}=$ Corner $\mathrm{C}$, Corner $\mathrm{D}$ average air temperatures

$T_{F}=$ average Freon temperature in $\mathrm{HX}$
}

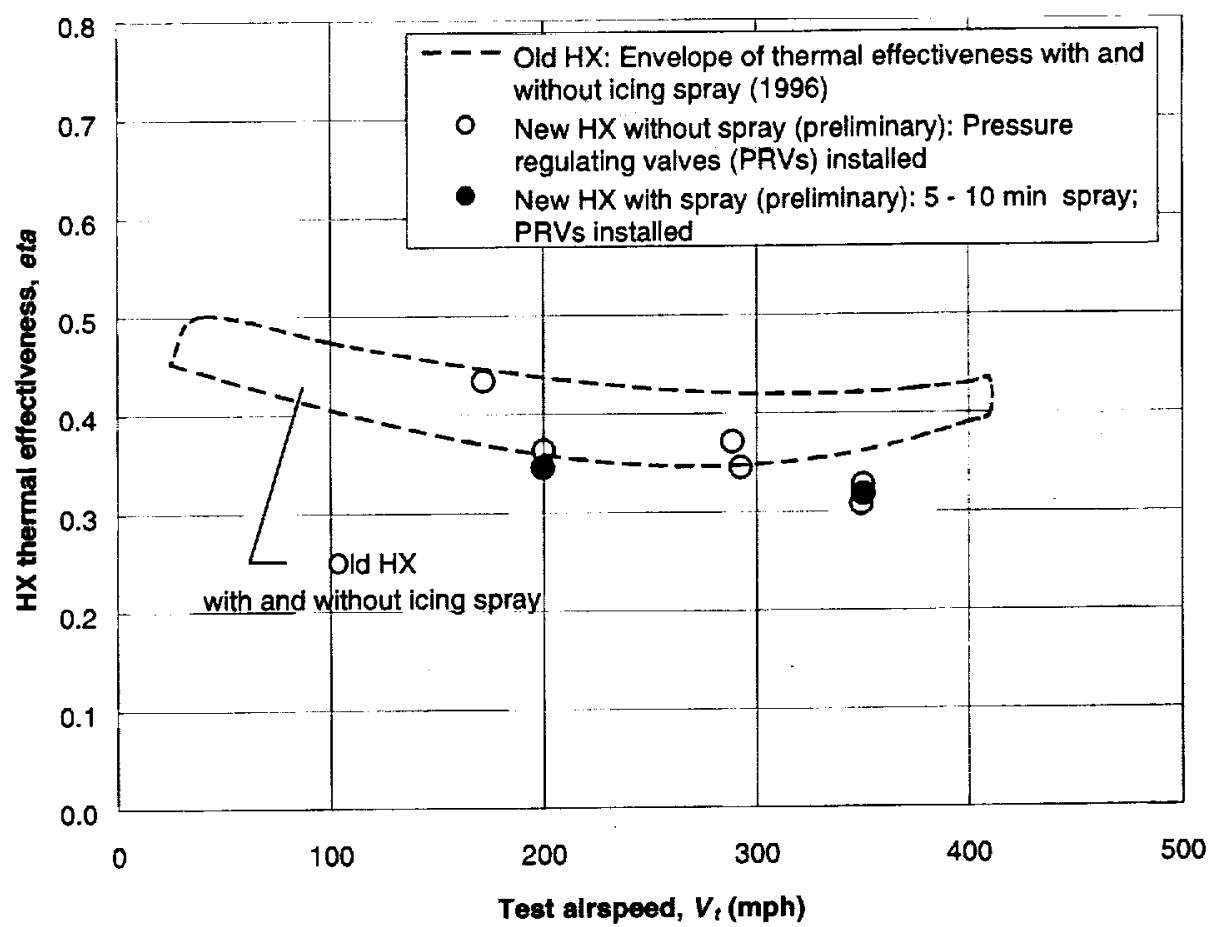

Figure 26. Preliminary comparison of the measured thermal effectiveness of the new $\mathrm{HX}$ with that of the original HX. 


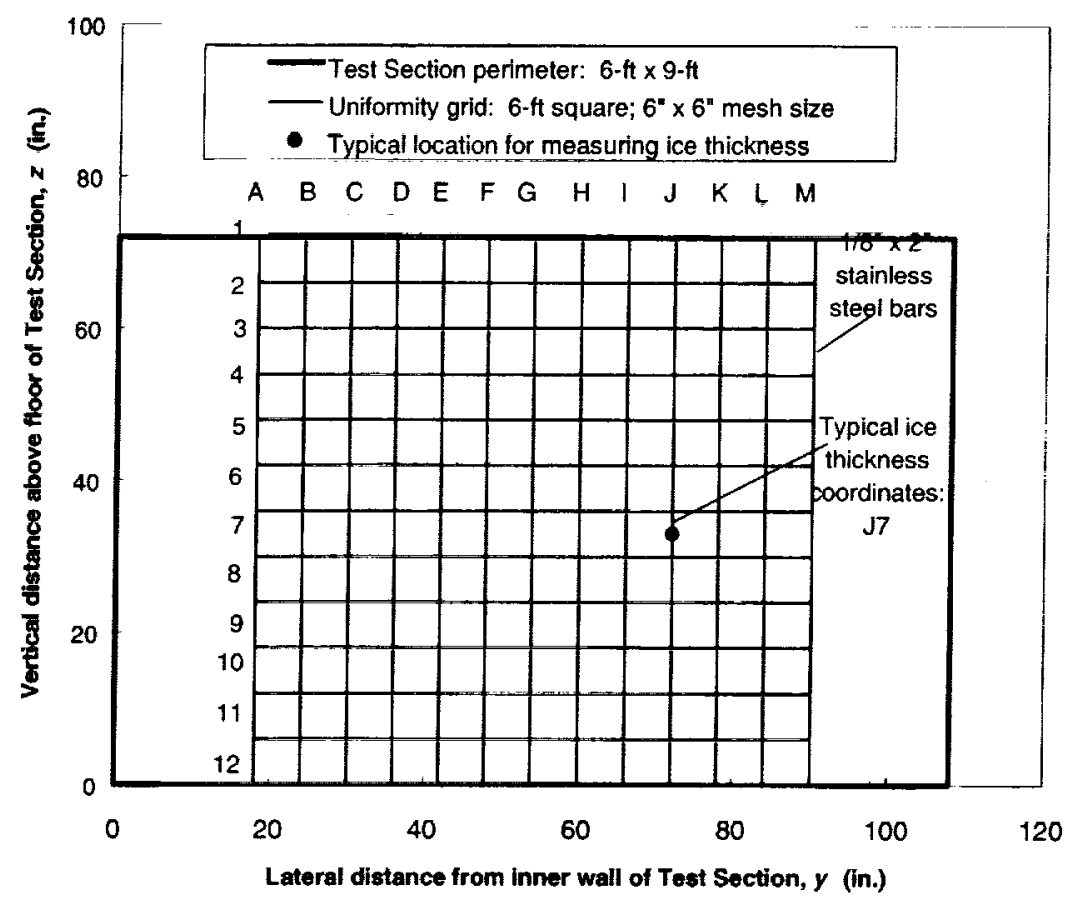

Figure 27. Layout of the grid of steel bars used to measure the uniformity of ice accretion in the IRT Test Section.

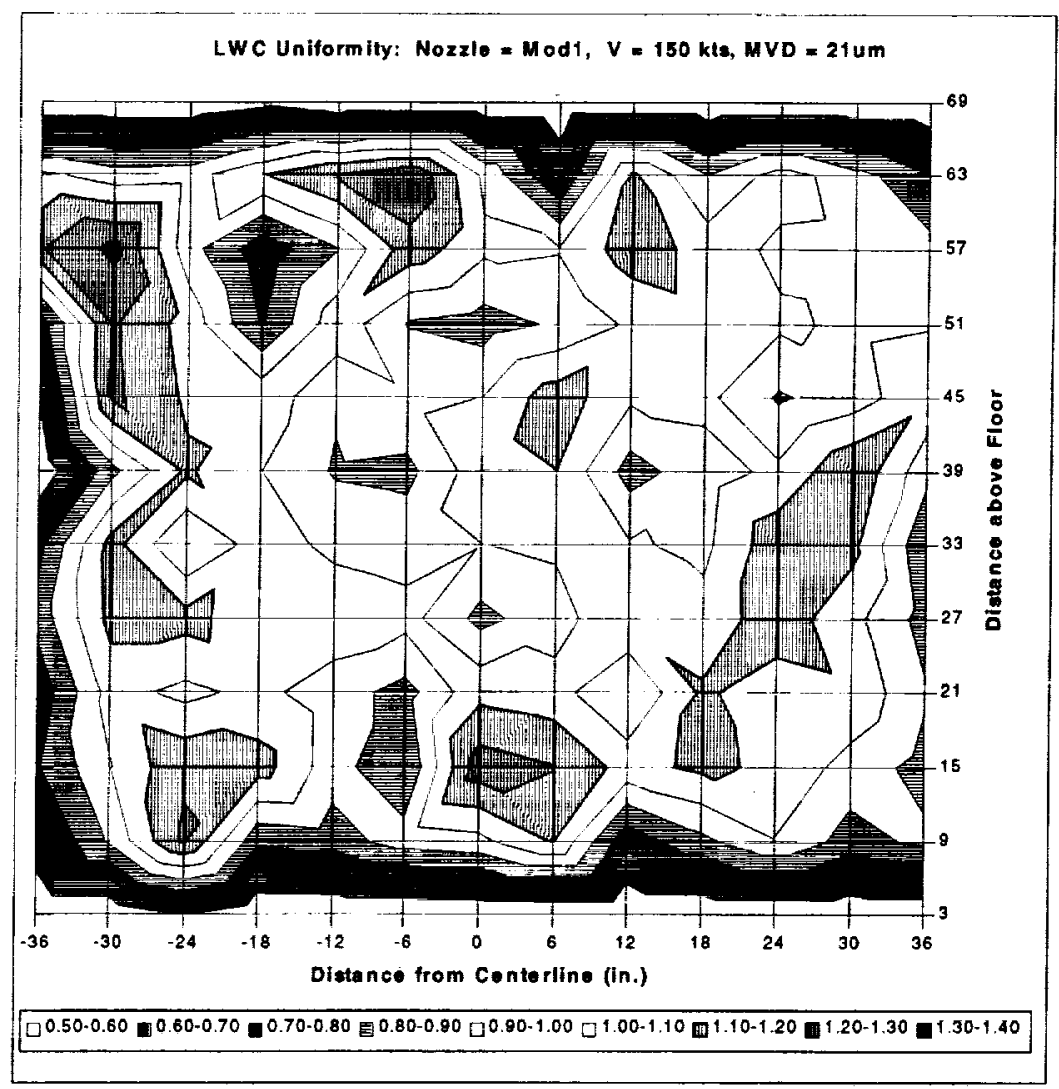

Figure 28. Typical contour plot of the variability of ice accretion across a 6-ft by 6-ft $(1.8-\mathrm{m}$ by $1.8-\mathrm{m})$ zone in the middle of the Test Section 


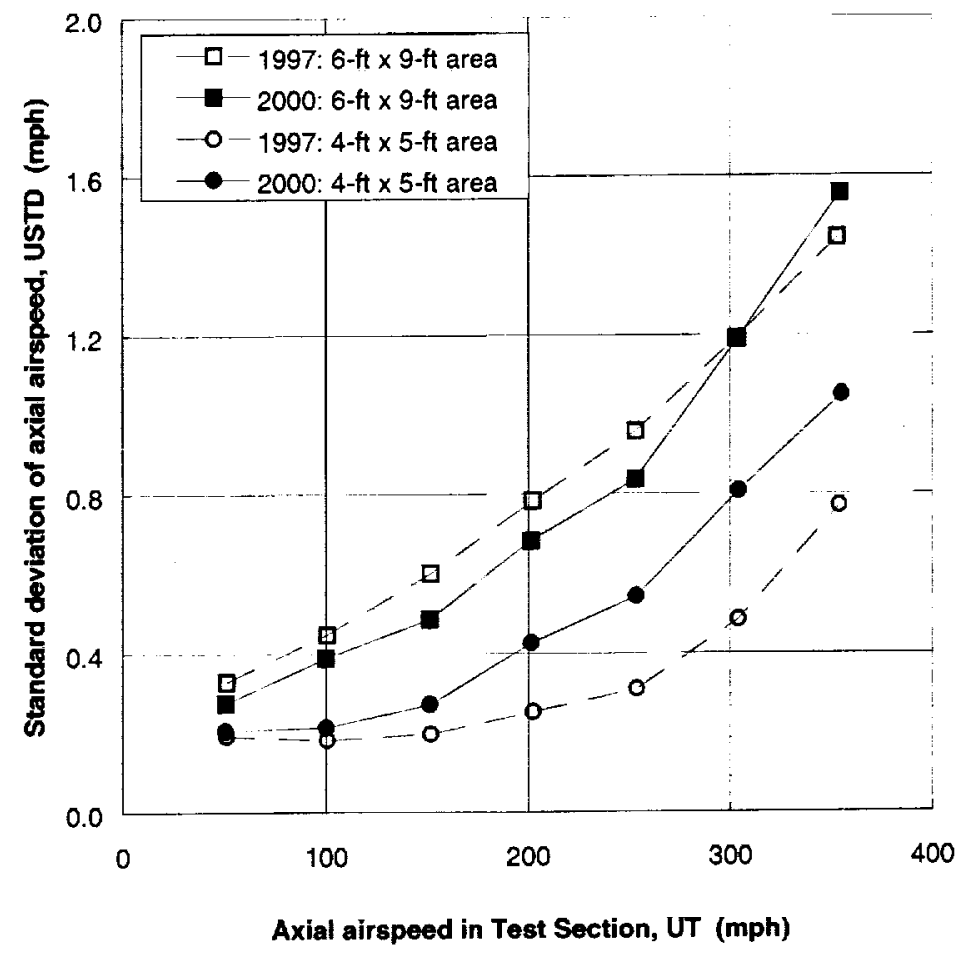

Figure 29. Standard deviation of axial airspeed in the middle of the Test Section, as a function of the test airspeed. Airspeed deviations in the modified IRT are compared with measurements made in 1997.

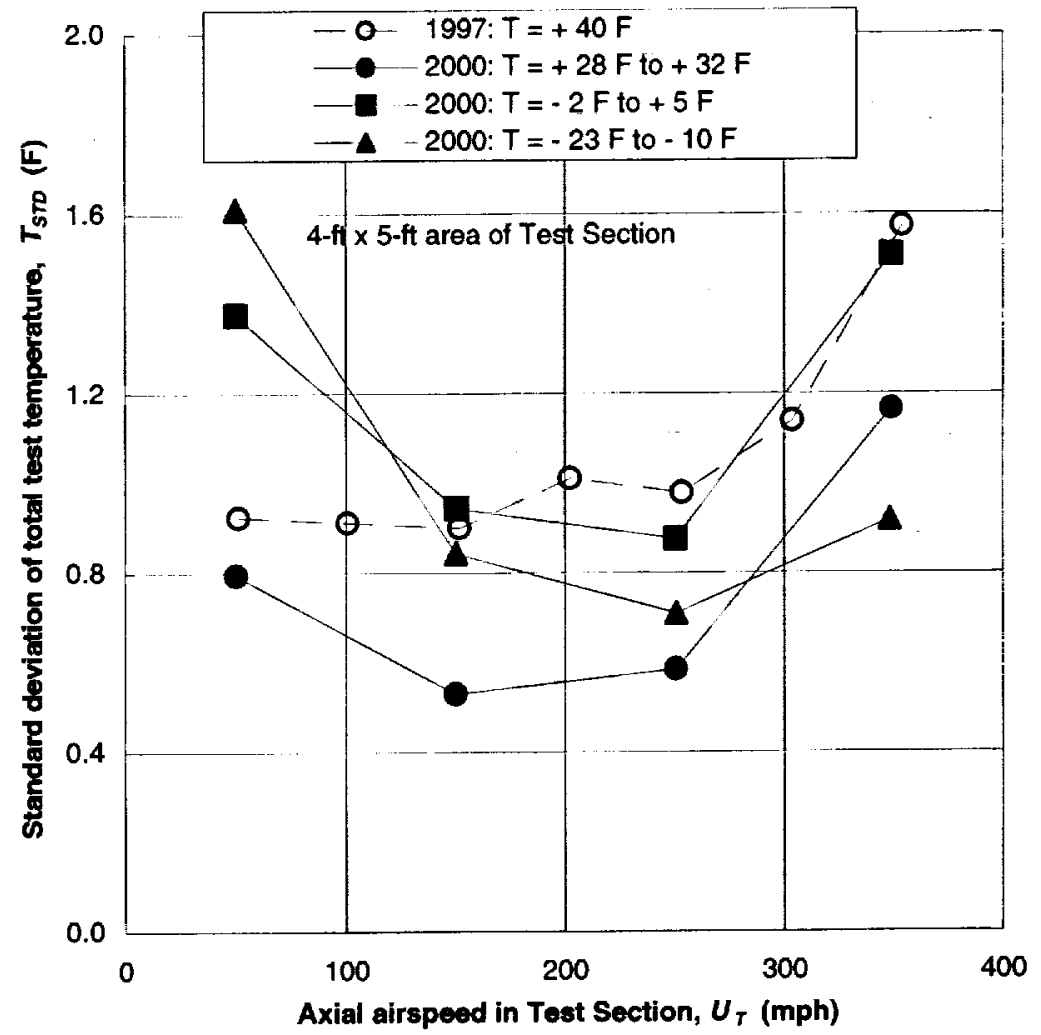

Figure 30. Standard deviation of total test temperature in the middle of the Test Section, as a function of the test airspeed and temperature. Temperature deviations in the modified IRT are compared with measurements made in 1997. 


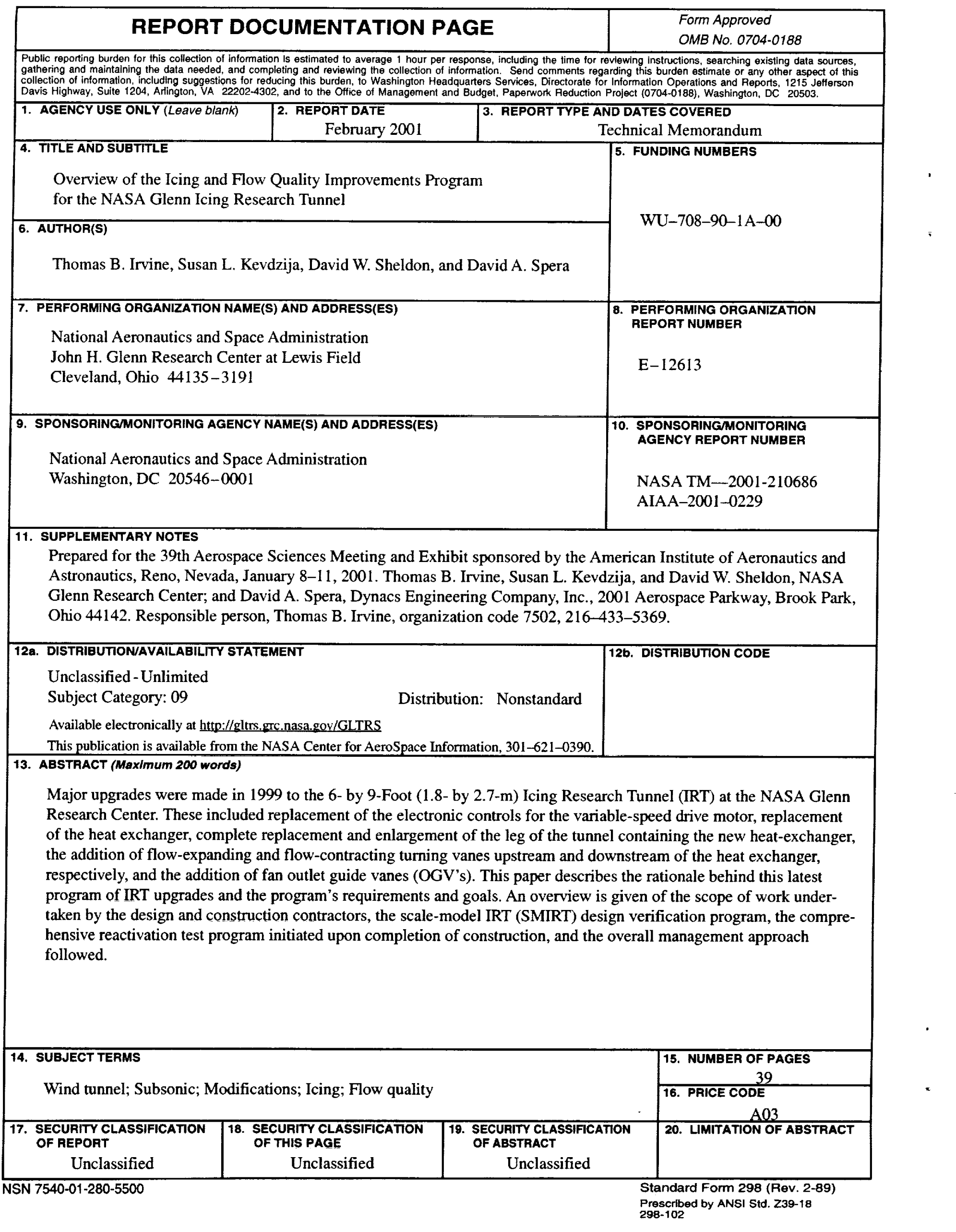

